NBER WORKING PAPER SERIES

\title{
EXPLAINING DIVERSITIES IN AGE-SPECIFIC LIFE EXPECTANCIES AND VALUES OF LIFE SAVING: \\ A NUMERICAL ANALYSIS
}

\author{
Isaac Ehrlich \\ Yong Yin \\ Working Paper 10759 \\ http://www.nber.org/papers/w10759
}

\author{
NATIONAL BUREAU OF ECONOMIC RESEARCH \\ 1050 Massachusetts Avenue \\ Cambridge, MA 02138 \\ September 2004
}

An earlier draft of this paper was distributed at the National Bureau of Economic Research Health Economics Spring Meeting. We are indebted to Michael Grossman and the participants in the meeting for helpful comments, and to Dhaval Dave for assistance with data sources. The views expressed herein are those of the author(s) and not necessarily those of the National Bureau of Economic Research.

(O)2004 by Isaac Ehrlich and Yong Yin. All rights reserved. Short sections of text, not to exceed two paragraphs, may be quoted without explicit permission provided that full credit, including $\odot$ notice, is given to the source. 
Explaining Diversities in Age-Specific Life Expectancies and Values of Life Saving: A Numerical Analysis

Isaac Ehrlich and Yong Yin

NBER Working Paper No. 10759

September 2004

JEL No. C6, D8, I1

\begin{abstract}
$\underline{\text { ABSTRACT }}$
Little attempt has been made so far to quantify the extent to which individual willingness to spend on life protection may account for the observed trends and diversities in agespecific life expectancies across individuals and over time. We address these issues via calibrated simulations of a dynamic, life-cycle model of life protection in which life's end is a stochastic event, age-specific mortality risks are endogenous variables, and spending on life protection is set jointly with related insurance options: life insurance as well as annuities. A unique feature of our model is that it links age-specific mortality risks and implicit private values-of-life-saving (VLS) as "dual variables", and estimates them jointly. It also offers new insights about the concept and measurement of VLS. Life protection is estimated to have a non-negligible impact on age-specific life expectancies. It can account for significant portions of observed inequalities in life expectancies across population groups and over time, as well as for a wide range of empirical estimates of VLS produced via the conventional "willingness to pay" approach.
\end{abstract}

Isaac Ehrlich

Department of Economics

State University of New York at Buffalo

Buffalo, NY 14260

and NBER

mgtehrl@buffalo.edu

Yong Yin

Department of Economics

State University of New York at Buffalo

Buffalo, NY 14260

yyin@buffalo.edu 


\section{INTRODUCTION}

Despite the persistent upward trend in longevity in the developed world, there has been little attempt by economists to quantify the importance of individual efforts at health and life protection in explaining the trend and persistent disparities in age-specific life expectancies across population groups ${ }^{1}$. Studies that address the determinants of life expectancy generally rely on life-cycle models treating life's end as known with certainty (see references in Forster, 2000). Most also estimate reduced-form equations of an underlying theoretical structure, which are not derived from the theoretical structure itself (see references in Gerdtham et al., 1999, and Barlow and Vissandjee, 1999). Expanding on the approach developed in Ehrlich (2000), we redress these issues through calibrated simulations of a dynamic life-cycle model of life protection where life's end is an uncertain event, life-cycle consumption and savings plans are influenced by related insurance options, and age-specific mortality risks, hence life expectancy, are endogenous variables. This enables us to address the demand for life expectancy as a direct choice variable. A unique feature of our model is that it links age-specific mortality risks and implicit private values-of-life-saving (VLS) as "dual variables", and estimates them jointly.

Our key assumption is that age-specific mortality risks can be lowered on the margin from biologically endowed levels that continuously rise with age (at least from adulthood), through self-protective inputs. These include preventive medical care services, diet and exercise, and myriad safety measures, collectively termed "life protection". Individuals can also insure against mortality risks by purchasing both life insurance and annuities. The model's control variables thus include age-specific consumption and bequest (accumulated ordinary savings and life insurance) as independent choice variables, in addition to 
willingness to spend on life protection. A key co-state variable affecting the latter is the 'shadow price of life protection', also known as the 'value of life saving' (VLS).

As previous literature emphasized (see e.g., Yaari, 1967, Thaler and Rosen, 1975, Davies, 1981, Arthur, 1981, Shephard and Zeckhouser 1982, Philipson and Becker, 1998, and Johansson, 2001), recognizing longevity as uncertain can change the standard economic predictions about life-cycle choices. We go beyond these models by treating the risk of mortality and age-specific VLS as endogenous variables, along with consumption and bequest (life insurance as well as annuities). This complex framework does not yield explicit solutions for our three endogenous variables. Ehrlich (2000) derived such solutions by treating life protection as predetermined. In this study, we provide unconditional solutions for all three choice variables, using numerical methods.

The model's parameters are, in principle, estimable statistically, but the individual lifecycle data required for such estimation are not fully available. We rely, instead, on calibrated simulations of our model's basic parameters, based on representative group data. Our analysis is facilitated by a number of simplifying assumptions, which permit the use of the model's optimality conditions in the simulations. To account for major life protection inputs, we use an aggregate spending measure, which we calibrate empirically to incorporate estimated spending on preventive medical care, workplace safety measures, and health-enhancing goods and services (life style). We generally treat life protection as a flow, rather than a stock variable, but we also use our methodology to account for the durability of life protection over finite periods. We assume that annuities and life insurance are available to individuals in private insurance markets at actuarially fair terms, but we also develop insights about the impact of social security on optimal life protection. 
Despite these simplifications and related data limitations, our simulations are found to account for a non-trivial portion of observed variations in life expectancies by age and population groups, as well as for a wide range of empirically estimated VLS levels. They also yield insights about the relative importance of basic determinants of life protection.

Value-of-life-saving estimates have so far been derived mainly through regression estimates of "willingness to pay" (WTP) opportunity costs for marginal reductions in mortality risks, based on compensating wage or price differentials in activities associated with varying risks to life. But these regressions treat observed mortality risks as exogenous variables, whereas we treat observed probabilities of mortality as endogenous outcomes of WTP directly for optimally determined life protection. We are thus able to link variations in age-specific life expectancies with their implicit VLS counterparts over the life cycle as well as in the cross section (see Viscusi, 1993 and Viscusi and Aldy, 2003). ${ }^{2}$ Moreover, our analysis enables us to offer new insights into the concept and measurement of VLS.

We conduct two types of calibrated simulations. In the first, we rely on the observed rates of age-specific mortality risks for the general population (our benchmark group), as reported by Vital and Health Statistics of the US [VS], to impute the corresponding optimal spending on life protection and age-specific "biological" mortality risks. The differences between the realized and projected risks indicate the quantitative impact of life protection on realized life expectancy levels.

In the second, we use the imputed biological mortality risks for our benchmark group to project the realized risks of different educational groups, and of our benchmark group over time. These simulations permit an assessment of the model's power to explain diversity in life expectancies in the population. They also provide alternative age-specific VLS 
estimates based on a conventional "willingness to pay" approach, which highlight the dependence of VLS estimates on the length of the interval of time over which they are measured.

We proceed as follows: Sections I and II introduce our model and simulation procedure. In section III we calibrate our benchmark case. In sections IV and V we conduct simulations explaining life expectancy variations across individuals, groups, and over time. We conclude by assessing the model's power to explain the apparent variability in both life expectancies and empirically estimated magnitudes of 'value of life saving'.

\section{The Theoretical Model And Its Numerical Solution}

The essence of our theoretical approach is the correspondence between efforts to reduce mortality risks, which we call "life protection", and the standard definition of what the literature calls "value of life saving". Under static conditions, the prospect of mortality means facing a pair of conditional outcomes: a consumption plan if alive $(\mathrm{G})$, subject to a wealth constraint $(W)$ net of life-protection outlays (s), G = (W-s) with utility level $U(G)$, or a bequest plan $\mathrm{B}=(\mathrm{W}-\mathrm{s})$, subject to the same constraints but yielding a lower utility level V(B). The underlying mutually exclusive states of the world are "life" and "death", with probabilities (1-p) and $p$, respectively. Life protection outlays (s) are designed to lower $\mathrm{p}$, where $\mathrm{p}(\mathrm{s})$ is a continuously differentiable and strictly concave function of $\mathrm{s}$, and $\mathrm{p}^{\prime}(\mathrm{s}=0) \rightarrow \infty$. Optimal life protection requires as a necessary condition the equality between the marginal cost of life protection and its marginal benefit:

(1) $\left[-p^{\prime}(s)\right]=\left[(1-p(s)) U^{\prime}(G)+p(s) V^{\prime}(B)\right] /[U(G)-V(B)]$.

Equation (1) restates the optimal "self-protection" decision in Ehrlich and Becker [EB] (1972). Taking its inverse value we obtain: 
(2) $\left.\mathrm{v}(\mathrm{s}) \equiv-\left[1 / \mathrm{p}^{\prime}(\mathrm{s})\right]=[\mathrm{U}(\mathrm{G})-\mathrm{V}(\mathrm{B}))\right] /\left[(1-\mathrm{p}(\mathrm{s})) \mathrm{U}^{\prime}(\mathrm{G})+\mathrm{p}(\mathrm{s}) \mathrm{V}^{\prime}(\mathrm{B})\right]$

The numerator of (2) defines the difference in utility between being alive or dead and the denominator of (2) defines the marginal expected utility of wealth. Their ratio defines the "shadow price of life protection", or "willingness to pay" for a marginal reduction in the probability of mortality - better known as the "value of life saving" (VLS). Optimal selfprotection and VLS are thus shown to be two sides of the same coin. In EB's model, the self-protection decision is determined jointly with a "market insurance" alternative.

The model we specify and simulate in this paper is a generalization of this marketinsurance-self-protection paradigm in several ways: it is formulated as a continuous-time, life-cycle consumption prospect subject to stochastic odds of survival to any point in time ("age"), under a given age-earnings profile and an initial wealth level, which is inherited as the optimal bequest left by an earlier generation. It is also a generalization of the "insurance" problem analyzed in EB in that two types of "market insurance" are recognized simultaneously: insuring survivors' needs in the event of ones' premature death (life insurance), and insuring one's own old-age needs arising from unanticipated longevity (annuities purchase). The availability of a market for actuarial notes allows us to solve for optimal consumption and bequest paths separately over the life cycle, to estimate the "market" value of human wealth under uncertain work horizons, and to link optimal bequest of an older generation with initial wealth of its offspring.

The formal model is outlined in Appendix A. Here we introduce its basic components. We assume that the survival probabilities between any two points in time follow a generalized Poisson process: $S(i, j)=\exp \left[-\int_{i}^{j} f(t) d t\right]$, where $f(t)$ is the time-varying hazard 
that death would occur at $t$, given survival to $t$. We specify this conditional hazard rate, $f(t)$, or "force of mortality", to be controllable on the margin by a concurrent aggregate life protection measure, $\mathrm{I}(\mathrm{t})$, which is an increasing function of own time $(\mathrm{m})$, preventive health care and safety measures (M), personal efficiency proxied by education (E), and a given health-care technology $\theta$, i.e., $\mathrm{I}(\mathrm{t})=\mathrm{I}(\mathrm{m}(\mathrm{t}), \mathrm{M}(\mathrm{t}) ; \mathrm{E}(\mathrm{t}), \theta(\mathrm{t})){ }^{3}$. Life protection lowers the natural, or biological hazard rate, $\mathrm{j}(\mathrm{t})$, which continuously rises with age (at least from adulthood), i.e., ${ }^{0}(t)>0$. For convenience, we define the output of life protection efforts in units of mortality rates, so $f(t)=j(t)-I(t) \geq 0$.

Life protection output is assumed to be subject to diminishing marginal productivity, largely because of the finiteness of the human body. The cost of life protection is thus specified as an increasing cost function, $\mathrm{C}(\mathrm{t})=\mathrm{cI}(\mathrm{t})^{\alpha}$, where $\mathrm{c}$ is the cost of providing "one unit" of $\mathrm{I}(\mathrm{t})$, and $\alpha>1$. This one-unit cost is generally a function of given health-services market price and medical technology and one's wage and human capital (education) paths, or $\mathrm{c}(\mathrm{t})=\mathrm{c}(\mathrm{Pm}, \theta, \mathrm{w}(\mathrm{t}), \mathrm{E}(\mathrm{t}))$, respectively. Since the wage (opportunity cost of time) is itself a function of human capital, $w(t)=w(E(t))$, and the two have opposite effects on $c$, we abstract from any drift in c over the life cycle or in the cross section, by invoking a "neutrality" assumption about the net effect of human capital on unit costs. ${ }^{4}$

We assume the existence of competitive markets for actuarial notes (life insurance and annuities) that are actuarially fair to individuals. This simplification enables us to treat real “consumption" spending Z(t) (net of life protection) and bequest B(t), i.e., life insurance and accumulated ordinary savings (which survive one's death), as separate objects of choice, along with life protection, as well as to derive conditional closed-form solutions for 
our control variables. It also facilitates the assessment of the "market" values of both human wealth, i.e., the capitalized value of future earnings stream net of life protection costs $\mathrm{L}(\mathrm{t})$, and non-human wealth, $\mathrm{A}(\mathrm{t})$, i.e., the annuity-equivalent of regular savings and all annuities, as defined in equations (A.2a) and (A.3a) in Appendix A.1. The objective function is the additive expected lifetime utility $(\mathrm{J})$ having a stochastic time of death, $\widetilde{\mathrm{D}}$ :

(3) $J(A(t), t ; \eta)=\operatorname{Max}_{Z, B, I} E\left\{\int_{t}^{\tilde{D}} \exp [-\rho(s-t)] U(Z(s)) d s+\exp [-\rho(\tilde{D}-t)] V(B(\tilde{D}), t)\right\}$, where $\mathrm{U}(\mathrm{Z})=(1 / \mathrm{k}) \mathrm{Z}^{\mathrm{k}}, \mathrm{V}(\mathrm{B}, \mathrm{t})=[\mathrm{n}(\mathrm{t}) / \mathrm{k}] \mathrm{B}^{\mathrm{k}}, 0<\mathrm{k}<1$ to assure concavity, $\rho$ is a subjective discount factor, and $\eta$ is a parameters vector. The expectation operator $E$ is defined over the density function of the endogenous mortality risks. Since age at death $\widetilde{D}$ is stochastic, the optimization problem must be defined over some planning horizon $\mathrm{D} \leq \infty$. The boundary conditions restrict annuity wealth, $\mathrm{A}(\mathrm{t})$, to be exhausted at $\mathrm{D}$ (see equation A.4).

To facilitate the dynamic simulations, the model treats life protection as a flow variable. In section IV.C.1, however, we simulate the model by allowing life-protection to have a durable effect on future mortality rates. Also, we do not model morbidity risk (health) as a direct argument entering the utility function, although implicitly we take it to be monotonically related to mortality risk (see Ehrlich, 2000), since the material impact of life protection on morbidity is captured by the actual earnings data we use in our simulations, w(t), which reflects labor time lost to illness. To mitigate the omission of health as utility, however, we also conduct simulations in which the value of healthy time is imputed as part of our definition of "full earnings" (see subsection IV.B.5).

Equation (3) allows for "bequest" just as a financial legacy. It thus implicitly includes in "consumption" any investments a family head makes in raising and educating children, 
who provide altruistic benefits as well as informal-care and support at old age. The accumulated financial wealth we derive should thus be interpretable as accounting, in part, for such parental investments. In addition, the model assumes all annuities to be private, although in practice annuity income and related taxes come largely from social security. In our baseline simulations $\mathrm{A}(\mathrm{t})$ thus accounts, in principle, for social security as well. In section IV.C.2, however, we treat social security wealth as a separate wealth component.

The first-order optimality conditions are given in Appendix A. The model's parameters are the age profiles of the biological mortality density $j(t)$, the real wage profile, $w[E(t)]$, and the time-invariant parameters associated with the real return on capital (r), and the utility and health-production cost functions $(\rho, k, n, c, \alpha)$ as defined above and in Appendix A. The optimized "control variables" are the time-varying paths of life protection, $\mathrm{I}(\mathrm{t})$, consumption, $\mathrm{Z}(\mathrm{t})$, and bequest, $\mathrm{B}(\mathrm{t})$, under a given planning horizon $(\mathrm{D} \leq$ $\infty)$. These dictate the resulting "state variables" paths - net human and non-human wealth, $\mathrm{L}(\mathrm{t})$ and $\mathrm{A}(\mathrm{t})$, and the mortality density function $\mathrm{f}(\mathrm{t})$, hence life expectancy $\mathrm{T}^{*}(\mathrm{t})$.

A key co-state variable in the model is the shadow price of life protection, measuring the value of a marginal reduction in the force of mortality, $\mathrm{f}(\mathrm{t})$, or the private value of life saving. Its optimal solution is given by

(4) $\mathrm{v}^{*}(\mathrm{t})=(1 / \mathrm{k}) \mathrm{L}(\mathrm{t})+[(1-\mathrm{k}) / \mathrm{k}]\left[\mathrm{A}(\mathrm{t})-\mathrm{B}^{*}(\mathrm{t})\right]=\mathrm{z}(\mathrm{t})[\mathrm{A}(\mathrm{t})+\mathrm{L}(\mathrm{t})]-\mathrm{A}(\mathrm{t})=\alpha \mathrm{c} \mathrm{I}^{*}(\mathrm{t})^{\alpha-1}$

with $A(t), L(t)$, and $z(t)>1$, defined in equations (A.2a), (A.3a) and (A.13) of appendix A.

The closed-form solution of $\mathrm{v}^{*}(\mathrm{t})$ in equation (4) represents a dynamic version of the static VLS in equation (2). Like equation (2) it is conditional, however, on the mortality density $f(t)$, which affects the values of $z(t), L(t)$ and $A(t)$ and is an endogenous outcome of optimal life protection, $I^{*}(t)$. The latter is found by equating the value of life saving with its 
marginal cost, $\mathrm{v}^{*}(\mathrm{t})=\alpha c \mathrm{I}^{*}(\mathrm{t})^{\alpha-1}$. The age-varying VLS can thus be inferred from the optimal "willingness to pay" for a marginal increase in life protection, which is determined jointly with optimal consumption and bequest, $\mathrm{Z}^{*}(\mathrm{t})$ and $\mathrm{B}^{*}(\mathrm{t})$ (see Appendix $\left.\mathrm{A}\right)$. Note that $A(t)-B^{*}(t)$ measures the optimal demand for annuities at different age levels.

An immediate implication of equation (4) is the greater importance of human relative to non-human wealth in determining age-specific VLS. The intuitive reason is that human wealth can be realized at any given age only upon survival to that age. It thus has a greater weight in determining the optimal path of life protection efforts over the life cycle.

It is impossible to obtain closed-form solutions for all endogenous variables, but we make use of conditional closed-form solutions of the system obtained by first taking life protection to be predetermined (see Appendix A.2). Here we derive unconditional solutions for all choice variables through an iterative procedure described below. The stochastic dynamic programming method used to solve the model (see, e.g., Judd, 1998) produces time-consistent life-cycle paths of these endogenous variables starting from any given age, $\mathrm{t}$, conditional on survival to $\mathrm{t}$.

\section{THE ITERATIVE METHOD}

We combine our conditional closed-form solutions for consumption, bequest, and the value of life-saving function along with the first-order condition for optimal life protection, as given in Appendix A, to derive unconditional solutions for all choice variables through an iterative procedure described in Appendix B.

As a starting point, we need to explain our treatment of mortality rates, which is a key input in our iterations. No data are available on "biological" rates, $\mathrm{j}(\mathrm{t})$. What we observe in practice are the actual mortality rates $f(t)$, which we take to be the difference between the 
biological rates and the impact of life-protection, or $f(t)=j(t)-I(t)$. In our benchmark case we then calibrate our simulations by taking the observed average mortality rates for the entire US population as the solution for $\mathrm{f}(\mathrm{t})$, and project the optimal age-profile of selfprotection activity that accounts for it. We thus impute the group's implicit biological mortality density $\mathrm{j}(\mathrm{t})$. For specific population groups, we can similarly impute groupspecific biological densities from the observed ones, if available, or use the imputed biological density for the benchmark group as the actual densities of the specific-groups. ${ }^{5}$

The simulations we conduct converge quite rapidly and smoothly under widely varying values of the model's underlying parameters. In most cases, the iterations converge on a stable solution after just 4 or 5 iterations. The solutions are also found to be locally unique, since when we use different starting values (initializations) of $\mathrm{I}(\mathrm{t})$ (see Appendix $\mathrm{B}$ ), the system converges on the same numerical solutions for all endogenous variables.

\section{CALIBRATING THE MODEL}

We calibrate the basic parameters of the model using actual data and independent studies. Some of our calibrations apply to the entire population (our benchmark group) while others vary across population groups, based on available data.

\section{A. Age-Specific Mortality Density}

We start with the observed profile of average age-specific mortality rates, $f(t)$, for the US population in 1996, which we take from VS (1999; Series 2, No. 129, Table 1). The VS life table contains discrete, and somewhat noisy annual death rates from age 0 to 100 . To smooth out this annual series, specified as a generalized Poisson density function, $\mathrm{f}(\mathrm{t})$, we convert it to a continuous function by assuming that $\mathrm{f}(\mathrm{t})$ follows a "local" linear trend within each year. We also take the growth rate of $f(t)$ at time $t$ to be the average growth rate 
of $f(t)$ over the time periods $t-1$ and $t+1$. The constant term of the projected linear trend is then derived from the constraint that the integral value of the affected fatality density should equal $-\ln \left(1-\mathrm{q}_{\mathrm{t}}\right)$, where $\mathrm{q}_{\mathrm{t}}$ is the death rate at time $\mathrm{t}$.

One remaining problem is that, while life tables end at age 100, we need to project mortality rates up to age 107 , and even up to 150 in our sensitivity analyses (see section III.E). Following the technical recommendation in the VS report, we extend our death rate series beyond age 100 using the relationship $1-\mathrm{p}(\mathrm{t}-1, \mathrm{t}) \equiv \mathrm{q}_{\mathrm{t}}=\mathrm{q}_{\mathrm{t}-1} \mathrm{e}^{\mathrm{k}_{\mathrm{t}}}$, where $\mathrm{k}_{\mathrm{t}}=\mathrm{k}_{85}+\mathrm{s}(\mathrm{t}-85)$, and the report's recommended values for $\mathrm{k}_{85}$ and $\mathrm{s}$.

\section{B. The Earnings Profile}

The age-earnings profiles we use are the average labor earnings of employees and selfemployed workers of different age groups as well as of different sex and schooling levels in 1996, as listed in the Statistical Abstract of the United States [SAUS] (1998, Table 246). These data are converted into a continuous wage profile, $w(t)$, by fitting a cubic trend, since market wages are reported only up to age 65 and are projected to age 80 , assuming that earnings are negligible past that age. While our model is interpretable as relating to "fullearnings", including the value of healthy time in both life protection and home production, we allow for arbitrary estimates of the latter only as part of our comparative dynamics and sensitivity analysis. In our baseline simulations we use reported labor earnings and monetary spending to calibrate $\mathrm{w}(\mathrm{t})$ and the unit cost of life protection.

\section{The one-unit Cost of Life Protection}

An important challenge is estimating the "one-unit" cost of self-protection, c. The estimate we arrive at for our baseline group is c= 3.4 "units". ${ }^{6}$ We calibrate this parameter, 
based on our specification of the life-protection cost function, to ensure that our projected value of the average annual life-protection spending per person over the middle-age bracket 40 to 49 would account for available data on three major categories of life-protection spending (regardless of source of financing): "preventive" medical care, work-place safety costs based on mandated OSHA requirements, and private spending on diet and exercise representing preventive efforts associated with life-style choices.

Medical care expenditures by age are available from the Medical Expenditure Panel Survey of 1996. We distinguished discretionary "preventive care", which protects a person in a healthy state from reaching a potentially acute state of illness, from "remedial care", which is spent in a state of illness to avert potential life-threatening conditions, since theoretically, our life-protection spending is inherently discretionary. Based on an expert physician's assessment, we set the preventive care portion of total spending at $46.27 \%$, allowing for a range of deviations around this figure in our actual simulations. ${ }^{7}$ Assessments of the total cost of mandatory OSHA regulations per worker are hotly disputed in the literature - we have thus used a conservative lower-bound assessment, taken from Harvey (1998), by which this cost constitutes $0.866 \%$ of average annual wages. We extrapolated the annual spending on diet and exercise using Nachtrieb (2003). ${ }^{8}$

\section{Other Parameters}

Since there are no available data on individual financial endowments at age $18,(\mathrm{~A}(0))$, we impute this variable iteratively via our dynamic simulation procedure so as to match the expected value of bequest left by a parent who dies one generation ( 25 years) ahead (i.e., at age 43), discounted by the average mortality rates of parents through that age. We make the same adjustment to $\mathrm{A}(0)$ whenever we vary any of our basic parameters. For our 
baseline case, this method sets the financial endowment at $\mathrm{A}(0)=\$ 6,315$ (see IV.A).

We set the elasticity of utility with respect to consumption $k$ in equations (3) and (A.9) to be 0.5 , so the degree of relative risk aversion, $\mathrm{d}=(1-\mathrm{k})$, is 0.5 as well. The implied inter-temporal elasticity of substitution in consumption $(\sigma)$ is thus 2 , which falls within the range of estimated values of $\sigma$ in many econometric studies. The intensity of utility derived from bequest, $\mathrm{n}$ (see equation (A.10) in Appendix A), is calibrated to be constant at 1.2. ${ }^{9}$ Theoretically, $\mathrm{n}$ is the square root of the ratio of bequest to consumption in our model (see equations (A.14) and (A.15) in Appendix A). The Statistical Abstract of the United States for 1998 sets the total ordinary life insurance in force in 1996 (which we take to be the main indicator of intended bequest) at $\$ 8.337$ trillion, and personal consumption at $\$ 5.208$ trillion, producing a rounded ratio of 1.5 , and justifying $n=1.2$. The real interest rate, $\mathrm{r}$, is calibrated to be $3.2 \%$, a conservative estimate of the long-term real rate of return on a total portfolio of financial and non-financial assets, ${ }^{10}$ and the time preference parameter, $\rho$, is set at $1.5 \%$. This variable is calibrated so as to make our benchmark simulation of the non-human annuity-wealth accumulation per family head approach the level of mean family wealth, as gleaned from official statistics (see fn. 11).

We set the planning horizon to start at age 18 because market wage income prior to this age is quite low, and most juveniles do not make independent consumption, health, and bequest choices. Starting our simulations at age 18 (or 25 in section V.C) supports our treatment of schooling in this paper as a largely predetermined variable.

\section{E. The Planning Horizon.}

A critical parameter to be selected is the terminal point of the planning horizon, D. In principle D is infinite, as we place no upper limit on biological survival. We choose a finite 
horizon, however, because our stochastic dynamic optimization problem and our simulations require a finite $\mathrm{D}$, and because the rising biological mortality risks with age, and the finiteness of human wealth make it inexpedient to plan on potential survival beyond some distant, but finite age. Yet, to specify such an age a priori defeats the basic premise of the model, which treats survival probabilities as a choice variable.

A logical remedy would be to set D to be sufficiently distant so that the simulation results would be practically invariable to its value. This can be done by computing the maximized expected utility from living J(D) (see equation (3)) at alternative terminal planning dates. For any given set of parameter values, we plot J(D) as a function of D. The results, based on our benchmark parameter set, are striking. Figure 1 shows that although $\mathrm{J}(\mathrm{D})$ is a monotonically increasing function of $\mathrm{D}$, it becomes asymptotic to a finite level. Specifically, J(D) first rises sharply at young ages, then more slowly at older age levels, but becomes essentially flat after age 100 . The conventional stopping rule we adopt sets D at the point where the increase in $J(D)$ falls below $10^{-5}$ percent. This occurs at age 107 . Indeed, higher values of D result in virtually no changes in the solutions for the model's endogenous variables, and the solutions remain virtually identical regardless of whether we start our simulations at age 18 or at age 75 , for example. Our selected value of $D=107$ is not inconsistent with the sharp upward trend in longevity in the US.

\section{SIMULATION RESULTS}

\section{A. The Baseline Case}

The simulation results for our benchmark group (the total population) are presented in Table 1. Figures 2-6 also present the simulated age profiles of key variables: the value of human and non-human wealth, the value of life saving, $v(t)$, the actual vs. imputed 
"biological" mortality rates, $f(t) v . j(t)$, and the profile of the age-specific (remaining) life expectancy $T^{*}(t)$. We skip the age profiles of consumption $(Z)$ and bequest $(B)$, which are proportionally related $\left(B^{*}=n^{1 / d} Z^{*}\right.$ by equations A.14 and A.15) since the rate of growth of both is a constant, [(r- $\rho) /(1-\mathrm{k})]$, as can be shown using equations (A.7) and (A.5).

Figure 2 shows the age-specific (remaining) expected net human wealth $\mathrm{L}(\mathrm{t})$, representing the capitalized sums of remaining "net earning flows" (the difference between employment earnings and expenditures on self-protection), discounted for both the cost of future funds and mortality risks (see equation A.3a). While the observed earnings profile peaks at age 49 , human wealth peaks at age 29 and declines continuously afterwards. This profile reflects both increasing expenses for life protection and increasing fatality rates. Indeed, our simulated value of human wealth in Figure 2, based just on market wages, becomes negative after age 80 , which is our last age with (projected) positive earnings. In the following section, however, we also present simulations based on "full earnings" adjustments, designed to capture the value of healthy time in "home production" as well.

The annuity-equivalent non-human wealth age profile $\mathrm{A}(\mathrm{t})^{*}$ (Figure 3 ), defined in equation (A.2a), has the usual intertemporal humped shape, starting at an endogenously solved bequeathed endowment at age $18, \mathrm{~A}(0)$, and falling back towards $\mathrm{A}(\mathrm{D})=0$ at the end of the planning horizon. We link iteratively $\mathrm{A}(0)$ to optimal bequest from an older generation ( 25 years apart). In our benchmark case, planned bequest (transferable savings and life insurance) for a 43 -year old parent is projected at $\$ 31,575$. However, since only $20 \%$ of the parent's generation would expire by age 43 , we take $20 \%$ of $\$ 31,575$, or $\$ 6,315$, to be our benchmark inheritance level of an average offspring at age 18 (in a two-parent family with 2 children). Given our perfect capital market assumption, this figure stays the 
same regardless of whether the parent's death occurs at an age younger or older than 43, as long as the age gap between parent and offspring remains $25 .{ }^{11}$

Figure 4 shows the equilibrium age-specific 'value-of-life-saving' profile, $\mathrm{v}^{*}(\mathrm{t})$, defined in equation (4) and (A.13). Since the optimal value of life saving is also equal to the equilibrium marginal cost of (or "willingness to spend on") life protection, or $\mathrm{v}^{*}(\mathrm{t})=$ $\alpha c I^{*}(t)^{\alpha-1}$ (we set $\alpha=2$ in our baseline simulation), the $v^{*}(t)$ and $I^{*}(t)$ age-profiles share the same shape, and we therefore skip a separate presentation of $I^{*}(\mathrm{t})$. The $\mathrm{v}^{*}(\mathrm{t})$ profile is also hump-shaped, starting at a low level and falling to zero at the end of the planning horizon, D. In Figure 4, $\mathrm{v}^{*}(\mathrm{t})$ (in 1996 dollars) starts at $\$ 1.191$ million at age 18 , peaks at $\$ 1.435$ million at age 38 , and falls sharply after 48. This reflects the influence of the changing magnitudes of human and non-human wealth and the rates of return on annuities (see Table 2). Although the value of life saving falls to zero at the end of the planning horizon, it remains quite high through old age (see Table 1).

This pattern is somewhat different from the shape of the "value of life-extension" profile in Ehrlich and Chuma (EC) (1990), which is monotonically increasing with age, essentially because our model recognizes the potential of death at any age over the life cycle, rather than at an artificially assumed certain (though endogenous) age. Since the value of lowering the probability of mortality at a given age is influenced by the expected length of one's remaining (uncertain) life span, which shrinks as one advances in age, the value-of-life-saving profile in this analysis is more closely related to that of the "value of healthy life' in EC's paper. Indeed, an interesting feature of the simulated $v^{*}(t)$ profile in Figure 4 is that it remains fairly flat about the age in which it reaches its peak value. For the baseline case, $\mathrm{v}^{*}(\mathrm{t})$ varies less than $2.5 \%$ from its peak between age 30 and 46 . This 
remains the case for different parameter values of $\mathrm{n}$ and $\mathrm{k}$, or $\mathrm{r}$, except that the flat segment covers a different range of ages. For $r=4 \%$, for example, $v^{*}(t)$ varies less than $2.5 \%$ from its peak at age 55 between the years 44 and 65.

Figure 5 enables us to explore a central theme of the paper - the quantitative impact of life protection on the age-specific fatality rates and life expectancies - by comparing the actual and our imputed ("biological”) fatality rates. The plot reveals, not surprisingly, a diminishing importance of life-protection efforts in affecting rising mortality risks as the biological risks increase significantly, especially at older age levels. Over the average life span - ages 18 to 77 (the actual life expectancy at age 18) - average life protection, $\overline{\mathrm{I}}(\mathrm{t})$, is seen to account for $\mathbf{1 7 . 8 1 \%}$ of the projected average "biological" mortality risk, $\overline{\mathrm{j}}(\mathrm{t})$.

To complete the simulations, we also provide in Table 1 and Figure 6 the age profiles of life expectancy $T^{*}(t)=\int_{t}^{D} \exp [-m(t, u)] f(u)(u-t) d u$, where $m(t, u) \equiv \int_{t}^{u} f(s) d s$, based on both our estimated biological, and the actual, age profiles of mortality rates. The gap between the two indicates that life protection accounts for about 3.426 years, or a $6.16 \%$ improvement over our imputed "biological" life expectancy of our benchmark group at age 18 , and about 0.065 years, or $0.66 \%$ at age $77 .^{12}$

\section{B. Comparative Dynamics and Sensitivity Tests}

The simulations we conduct to estimate comparative-dynamic effects are based on our imputed biological, rather than the observed, age-specific mortality rates for the benchmark group, since the latter are endogenous in our model. The key results are summarized in Table 2. While all our reported simulations begin at age 18, we have also tested the sensitivity of our results to a starting age of 22 , partly to justify our treatment of 
schooling as a predetermined variable for our benchmark group. The results concerning projected mortality risks remain virtually unaffected (to the 4 th decimal point) by this change, and the differences concerning other endogenous variables are less than $1 \%$ at comparable ages. Comparative dynamic effects are assessed by varying the level of each of our parameters $25 \%$ above and below its calibrated value. ${ }^{13}$

\section{B.1. Varying relative risk aversion.}

Since a lower k implies a higher degree of relative risk aversion, we expect it to lower exposure to life-risking activities, i.e., to increase the value of life saving and the demand for life protection (see eq. 4). Changes in k may have little quantitative effect on net human wealth, $L(t)$, because of their opposite impacts on $f^{*}(t)$ and on spending on life protection (see eq. A.3a), but the impact on non-human wealth $A(t)$ can be higher: Greater relative risk aversion (a lower $\mathrm{k}$ ) increases consumption at young ages while reducing the optimal rate of growth of consumption and bequest, thus savings and asset accumulation.

Table 2 confirms these results. As $k$ falls from 0.625 to 0.375 , the peak $v^{*}(t)$ rises from $\$ 1.186$ to $\$ 1.823$ million at age 38; the gap between biological and actual mortality risks rises from 2.817 to 4.419 ; and life expectancy at 18 rises from 58.49 to 60.09 .

\section{B.2. Varying unit cost and marginal productivity of life protection.}

Table 2 indicates that larger values of $\mathrm{c}$ arising from higher medical care prices or a less effective medical technology $(\theta)$, greatly lower self-protection and life expectancy, especially at age 18 , but they marginally raise the value of life saving at all ages. This is not paradoxical. A larger c generates opposing effects on the demand for self-protection and its cost, thus on the value of life saving, $\mathrm{v}^{*}=\alpha \mathrm{cI}^{*}(\mathrm{c})^{\alpha-1}$ (see equation A.6). VLS can fall or rise as a result, depending upon whether the elasticity of demand for life protection 
with respect to c exceeds or falls short of 1 . Our simulations indicate that optimal lifeprotection, $I^{*}(c)$, falls by almost the same proportion as the increase in $c$; therefore a higher c slightly increases VLS: At age 38 , the peak value of $\mathrm{v}^{*}$ rises from $\$ 1.432$ to $\$ 1.437$ million as $\mathrm{c}$ rises from 2.55 to 4.25 . Average spending on life protection, $\operatorname{cI}^{\alpha}(\alpha=2)$, falls by about $50 \%$ at age 38 , while life expectancy at 18 falls from 60.29 to 58.39 .

The impact of an increase in the marginal productivity of life protection due the parameter $\alpha$ of the cost of life protection function $\mathrm{C}(\mathrm{t})=\mathrm{cI}(\mathrm{t})^{\alpha}$, has, of course, just the reverse effect to that of a higher unit cost of life protection, c. ${ }^{14}$

\section{B.3. Varying real interest rate.}

Theoretically, an increase in $\mathrm{r}$ lowers human wealth, $\mathrm{L}(\mathrm{t})$ and increases the rate of accumulation of non-human assets, $\mathrm{A}(\mathrm{t})$. The impact on the value of life saving, $\mathrm{v}^{*}(\mathrm{t})$, which is a non-linear function of $\mathrm{L}(\mathrm{t})$ and $\mathrm{A}(\mathrm{t})$ (see equation A.2a), is thus two-fold: a higher $r$ may increase $\mathrm{v}^{*}(\mathrm{t})$ at older ages, where $\mathrm{A}(\mathrm{t}) / \mathrm{L}(\mathrm{t})$ is relatively high, but it lowers it at young ages. These changes work to affect mainly the age at which $\mathrm{v}^{*}(\mathrm{t})$, hence life protection, $I^{*}(t)$, peak. These predictions are borne out by Figure 4 . The projected peak value of $\mathrm{v}^{*}(\mathrm{t})$ (1996 dollars) changes from $\$ 1.534$ million at age 28 , to $\$ 1.523$ million at age 55 as $r$ increases from $2.4 \%$ to $4.0 \%$. The corresponding impact on life expectancy is not monotonically related to $r$, and relatively modest, as shown in Table 2 .

\section{B.4. Varying bequest preferences}

By the conditional, closed-form solutions of our model (see equations (A.13)-(A.15)), a higher bequest preference lowers the demand for life protection, essentially because placing a higher value on the legacy to heirs lowers the marginal value of longevity. Our "bequest preference" parameter (n) captures, however, only benefits associated with 
financial legacy. Even under this limited bequest preference concept, however, Table 2 indicates that variations in $\mathrm{n}$ produce only minor changes. A higher $\mathrm{n}$ motivates a switch from own consumption to bequest (life insurance and regular savings), but also a higher asset accumulation to enable a higher bequest level. The optimal values of $v^{*}(t)$ and $I^{*}(t)$ thus fall only moderately as $\mathrm{n}$ rises.

\section{B.5. Varying wage income streams}

As already mentioned, reported age-earnings profiles, $\mathrm{w}(\mathrm{t})$, while capturing the return on healthy time (low morbidity risk) in the labor market, do not capture the full benefits of healthy time as a producer good. One way to account for the latter (assuming that mortality and morbidity risks are monotonically related) is to measure market earnings as "full earnings", incorporating the opportunity cost of healthy time in home production. Since no accurate measures exist, we experiment with implicit full earnings measures that are $25 \%$ or $50 \%$ higher than observed labor-market earnings. ${ }^{15}$

Higher full earnings raise human wealth (indirectly asset accumulation as well), and thus the demand for life protection, since the only way to secure future earnings is through survival. Indeed, $\mathrm{I}^{*}(\mathrm{t})$ and $\mathrm{v}^{*}(\mathrm{t})$ rise almost proportionally with $\mathrm{w}(\mathrm{t})$. In particular, the peak value of $\mathrm{v}^{*}(\mathrm{t})$ rises from $\$ 1.435$ to $\$ 2.141$ million as $\mathrm{w}(\mathrm{t})$ rises $50 \%$ from its reported level. The corresponding life expectancy at age 18 increases from 59.10 to 60.89 years.

\section{B.6. Varying initial endowments of non-human wealth}

Although equation (A.13) indicates that an exogenous change in $\mathrm{A}(0)$ would raise the value of life saving, the increase appears relatively modest in our simulations. When initial wealth increases from $\$ 6315$ by $25 \%$ or $50 \%$, peak $\mathrm{v}^{*}(\mathrm{t})$ rises from $\$ 1.435$ to $\$ 1.437$ or $\$ 1.439$ million at age 38. Note that the effect of a $25 \%$ increase in wage income, leading to 
an approximately equal percentage rise in human wealth at age $18(\mathrm{~L}(0))$, has a $24.5 \%$ larger effect on $\mathrm{v}^{*}(\mathrm{t})$, and a $25.7 \%$ larger effect on life expectancy at age 18 , than that of an equal percentage increase in the initial financial endowment, $\mathrm{A}(0)$. This confirms a key implication of our model about the larger importance of human wealth, relative to human wealth in determining the value of life saving (see section I and Appendix A.2).

\section{B.7. Varying health endowments}

It may appear that better endowed health, i.e., a lower biological mortality risk, $\mathrm{j}(\mathrm{t})$, could lower optimal life protection $\left(I^{*}(t)\right)$, as life expectancy then rises even without additional effort. Our model indicates, however, that the likely outcome could be a rise in life protection. This is because the wealth effect generated by a longer life expectancy increases the value of life saving. Indeed, although the rates of return on actuarial savings $(\mathrm{r}+\mathrm{f}(\mathrm{t}))$ fall, non-human wealth accumulation $\mathrm{A}(\mathrm{t})$ rises because of greater savings. More important, the capitalized values of human wealth $L(t)$ unambiguously rise because of the reduced mortality risks. Table 2 indicates that both optimal life protection outlays and life expectancy increase as $\mathrm{j}(\mathrm{t})$ decreases $25 \%$ about its projected age profile.

\section{Simulated Extensions of our Model}

\section{C.1. Allowing for durable effects of life-protection outlays.}

Our model treats life protection at a given age as impacting only contemporaneous mortality risks. A more general approach would be to allow for durable effects that last through future years as well. A full recognition of durability requires a significant generalization of our model, which we leave for future work. We can use the current framework, however, to assess the qualitative impact of a discrete change in the duration of life protection's impact through a simple experiment. 
Starting with our imputed "biological" mortality risks, $\mathrm{j}(\mathrm{t})$, we approximate the impact of higher (lower) durability of a given investment in life protection at age 39, I(39), by letting it cause an exogenous decline (increase) in the endowed mortality risks, $j(t)$, over the subsequent 10-year period, since the objective of the experiment is to assess how such implicit durability shift affects the entire age profile of optimal life protection, $I^{*}(t)$, hence $f^{*}(t)$, and $T^{*}(t)$. We carry out the simulations under two alternative assumptions: a. the impact of the shift will last for 10 years and then disappear at the end of the $10^{\text {th }}$ year; $b$. the impact would decay at a constant rate and become zero at the end of the $10^{\text {th }}$ year.

Naturally, an increase in the implicit durability of I(39) raises life-protection's efficacy, hence the demand for life protection, especially at relatively young ages, because life protection has a lingering effect on future as well as current mortality risks. At the same time, the fall in future mortality risks lowers the risk premium on annuities, which raises the discounted value of future wages, but lowers annuity wealth, which may lower the value of life saving at older ages. The net effect of higher durability appears to be a change in the age profile of life protection outlays. It raises life protection, and hence life expectancy, at younger relative to older ages, and these effects are naturally stronger the slower is the rate at which the investment impact depreciates. The changes in the age profiles of the value of life saving exhibit the same pattern (see Table 3A).

\section{C.2. The impact of social security}

Our model ascribes all annuity savings to private annuities. The impact of a pay-asyou-go, defined-benefits social security system can be integrated in our simulations by imposing social security taxes at working age levels, and adding the defined social security benefits at retirement ages for our benchmark group. Specifically, we imposed a $6.2 \%$ tax 
rate on the wage-income profile of our benchmark group in 1996, while adding untaxed benefits of $\$ 16,614$ post age 65 , using the web "calculator" of the Social Security Administration. We then recomputed the resulting age-earnings profile after applying the $6.2 \%$ tax rate to our smoothed earnings profile, as originally calibrated.

Accounting for social security as a distinct "annuity" program produces a significant change in the structure of life protection spending: since social security is a definedbenefits, rather than a defined-contributions, scheme, it is shown to create an incentive to postpone spending on life protection to later years, rather than earlier years, which are subject to actuarially unfair taxes. This is reflected by the commensurate change in the structure of $v^{*}(t)$. Furthermore, the simulations in Table 3B suggest that the existence of social security leads to higher life expectancies and VLS at older age levels (see Ehrlich, 2000, section VI and a related result in Philipson and Becker, 1998).

\section{APPLICATIONS OF THE BASIC MODEL}

We now proceed to examine the power of our model to explain, or project, diversities in age-specific life expectancies and values of life saving across population groups. These simulations are constrained, however, by the limited data available to calibrate group-specific parameters. Available data include mainly age-earnings profiles and age-specific mortality rates, or life expectancies. Little else is available for calibrating group- and age-specific parameters concerning home production, education, cost of life

protection, access to medical care, or access to financial markets. ${ }^{16}$ In the following section, we focus on explaining projected or observed differences in age-specific life expectancies and VLS among different educational groupings for the male population, and for the general population over time, since differences in group-specific earnings profiles 
may constitute a predominant source of heterogeneity across these population groups. In both cases we employ the biological mortality risks we imputed for our benchmark group, to project group-specific life expectancies and compare these to observed ones.

\section{A. Life Expectancy Gaps Across Schooling brackets}

Under the "neutrality assumption" invoked in our baseline case, education does not alter the "unit" cost of life protection, c, because it raises both efficiency at life protection and the opportunity cost of time devoted to it. Our model suggests, however, a more direct link between education and life protection: since the more educated possess relatively higher human wealth, $\mathrm{L}(\mathrm{t})$, they will have a higher incentive to protect this wealth through survival. To what extent would this factor alone explain the observed gaps in life expectancy across educational classes?

To answer this question, we impose a common profile of biological mortality rates for males of all educational classes - the $\mathrm{j}(\mathrm{t})$ density imputed in our analysis of US males in the preceding section (the emphasis on males is clarified below) - since no separate VS data are reported for specific classes. We then consider four education groups: those holding High School, Bachelor, Master, and Doctorate degrees. Wage income profiles for these groups are from the SAUS, 1998 Table 246, Earnings, by Highest Degree Earned: 1996.

The results are summarized in Table 4 . We start our simulations at age 25 , to allow for a reasonable representation of all education groups in the labor market. The simulations indicate that people with more education have a higher human and non-human wealth and thus value of life saving. They also spend more on consumption than others as a result of their greater total wealth. Their non-human wealth profile is thus relatively lower initially, but becomes higher at older age levels. The VLS profile peaks at age 37 for high school 
graduates and at age 40 for Doctorates. The peak values range from $\$ 1.282$ million for high school graduates to $\$ 3.228$ million for Doctorate holders.

Next we project the impact of the differential levels life protection undertaken by different educational groups on their life expectancies. These projections can be compared with life-expectancy estimates for males of all races by educational attainments in 1990 in Richards and Barry [RB] (1998, Table 5(a)), who linked death certificates data with attained individual schooling. Clearly, our educational categories are not fully comparable with those estimated by RB. Nevertheless, we come close to RB's estimated life expectancies for high school at most ages. Comparing the estimated life expectancy gap between those with high school v. a Bachelor degree in each study, our projected gap explains $47 \%(=1.43 / 3)$ of the actual gap estimated by RB at age $30,38 \%$ at age 38 , and $20 \%$ at age 55 (the latter two not shown in the table). Our projected life-expectancy gaps between those with high school and a Doctorate degree explain an even larger percentage of the actual gap estimated by RB between those with a High School v. the highest degree $(64 \%$ at age $30,51.5 \%$ at age 38 and $23.7 \%$ at age 55$) .{ }^{17}$

\section{B. The Overall Trend in Life Expectancy}

We next extrapolate the time trend of life expectancy for the average wage earner in the economy from 1996 backwards. Once again, the only variable readily available for calibration over time is the real wage income of the representative worker. ${ }^{18}$

The simulation analysis is similar to the one we performed in section IV. We take as a point of reference the "biological" age-specific mortality profile we estimated for our benchmark group in 1996, $\mathrm{j}(96)$, and project the realized age-specific life expectancies backwards over the period 1970-1990. We interpolate the shifts in the age-earnings profile 
based on the rate of growth in average wage income over the same period, as reported by USCB (2000). Our age-specific life expectancy projections are given for 5-year intervals at age 20 , to make them comparable to the actually reported age-specific life expectancies, which we take from National Vital Statistics Report and various volumes of Vital Statistics of United States. The results are summarized in Table 5.

The simulations explain a good part of the actual changes in life expectancy between 1970 and 1996. For the entire period between 1996 and 1970, our projected growth in the conditional life expectancy at age 20 explains $25.66 \%(=1.07 / 4.17)$ of the actual growth. For the more recent period between 1980 and 1996, our projected growth of life expectancy at age 20 explains $33.33 \%(=0.57 / 1.71)$ of its actual growth. This is not insignificant given that we do not allow for any improvement in medical technology. If we assume that our one-unit cost of life protection fell at an annual rate of 1\% over 1970-1990 as a result of improving life saving technologies (which is also the growth rate of the economy's total factor productivity), our simulations would now explain $37.65 \%$ of the growth in life expectancy between 1970 and 1996 or $56.73 \%$ of the growth between 1980 and 1996. This higher explanatory power reflects the considerable influence of c on life expectancy (see Table 2). As for imputed values of life saving, our simulations indicate that VLS increased by $1.56 \%$ per annum over the period $1970-1996$, which roughly mimics the growth rate of real wage earnings in that period.

\section{Alternative Values of Life Saving Computed via a Conventional WTP Approach}

The age-specific values of life saving (VLS) in Tables 1-4 are simulated by solving for the marginal cost of life protection, $\left[\alpha c \mathrm{I}(\mathrm{t})^{\alpha-1}\right]^{*}$ since its equilibrium value is equated to the shadow price of life protection, $\mathrm{v}^{*}(\mathrm{t})$. This method of solving for VLS illustrates a direct 
"willingness to pay" (WTP) approach, since $\mathrm{v}^{*}(\mathrm{t})$ thus measures the willingness to pay for the added life protection costs needed to gain the utility benefit from a marginal reduction in the conditional mortality hazard rate at a point in time (see equation A.6). By comparison, conventional WTP measures of VLS are based on regression estimates of wage premiums workers are willing to forgo for bearing marginally lower occupational mortality probabilities, typically over a given year. These measure "compensating" wage differentials, assuming workers are homogeneous and labor markets are competitive.

Our model can be used to simulate analogous WTP estimates. In the illustration below, we raise the density function of $j(t)$ of our benchmark group to effect (via proper integration) an exogenous rise in the probability of mortality $\Delta \mathrm{p}(\mathrm{t})$ by $1 / 10000$ over one year (age). We next simulate the optimal increase in the annual wage flow, $\Delta \mathrm{w}^{*}(\mathrm{t})$, needed to keep expected lifetime utility intact. VLS is the ratio of the two, $V^{*}(t)=\Delta w^{*} / \Delta p(t)$.

Our two VLS measures are conceptually different. $V^{*}(t)$ is defined over an interval of time, while $\mathrm{v}^{*}(\mathrm{t})$ is defined at a point in time. Which concept is relevant empirically depends on whether individuals perceive of the relevant risk to their life as being operational over an interval of time, and adjust their plans accordingly, or whether they react to the conditional hazard rates they face at any moment in time. Both concepts are valid under different circumstances or institutional arrangements.

Technically, in a continuous-time setting the time-interval estimate of VLS, $\mathrm{V}^{*}(\mathrm{t})$, is an approximation of its point estimate, $\mathrm{v}^{*}(\mathrm{t})$. To simulate the latter using compensating wage differentials, the change in the mortality density must be imposed over an infinitesimally short time interval, rather than over one-year. Indeed, as we narrow down the time interval used for computing $\mathrm{V}^{*}(\mathrm{t})$, its value approaches that of $\mathrm{v}^{*}(\mathrm{t})$. The simulations show that the 
estimated age-specific values of $\mathrm{V}^{*}(\mathrm{t})$, assessed over a one year period, are roughly $84 \%$ higher than those of $\mathrm{v}^{*}(\mathrm{t})$ at all ages, essentially because of the greater loss of utility from adjusting to an interval change in probability of mortality, rather than adjusting continuously to changes in the mortality density all along the time interval. ${ }^{19}$ But the age profiles of $\mathrm{v}^{*}(\mathrm{t})$ and $\mathrm{V}^{*}(\mathrm{t})$ are virtually identical when adjusted for scale (see Table 6 ).

Despite their methodological similarity, our numerical estimates of $\mathrm{V}^{*}(\mathrm{t})$, while closer in magnitude reported regression estimates of VLS (see, e.g., Viscusi 1993), are not comparable to the latter for three main reasons: a. The estimated $\mathrm{V}^{*}(\mathrm{t})\left(\right.$ or $\left.\mathrm{v}^{*}(\mathrm{t})\right)$ do not account for the utility gain from reduced morbidity or injury due to life protection, although our earnings data do reflect corresponding earnings gains. On this score, our $\mathrm{V}^{*}(\mathrm{t}) \mathrm{s}$ may typically underestimate the empirically estimated VLS, which are based on the wage compensations accepted by workers for assuming higher mortality and morbidity risks; $b$. The empirical studies take the observed differences in mortality probabilities, say, across occupations, to be nature's choice, although by our analysis, they are endogenous variables. Our simulations indicate that increases in exogenous mortality risks $(\mathrm{j}(\mathrm{t})$ produce smaller increases in observed risks due to the intervening effects of life protection; treating observed risks as exogenous can thus result in overstated values of VLS; c. We project a wide diversity of $\mathrm{V}^{*}(\mathrm{t})$ by age, which regression estimates of VLS do not pin down.

\section{CONCLUSION}

The primary contribution of this paper is methodological: projecting jointly variations in age-specific life expectancies and values of life saving (VLS) by simulating a life-cycle model with endogenous mortality risks. Although the iterative methodology we use is well known, its application to a stochastic-dynamic model of life protection with endogenous 
risks of mortality is novel, especially our iterative determination of a finite planning horizon along with the model's control and state variables. Although the magnitudes of the numerical solutions must be viewed with caution, their relative variations suggest that life protection plays a non-trivial role in explaining observed disparities.

To highlight some of our results: For our benchmark group (the entire US population), average life protection $\overline{\mathrm{I}}(\mathrm{t})$ is projected to account for a $17.81 \%$ reduction in the unobserved average level of "biological" mortality hazards $\bar{j}(t)$ between ages 18-77. This may be a conservative estimate since our model abstracts from the utility value of lower morbidity due to life protection. The impact on life expectancy at age 18 (6.155\%) fluctuates within a range of $4.23 \%-9.37 \%$, or $2.355-5.218$ years, if we allow for a $25 \%$ change in our basic parameters separately. These estimates are little affected if we allow for varying durability of life protection, which generally raises the incentive to engage in life protection at younger, relative to older ages, or if we introduce a balanced PAYG social security, which mainly delays the age at which VLS and life protection peak.

In terms of the relative impact of different determinants of life protection, which may also vary across different population groups, $1 \%$ lower unit cost of life protection or higher relative risk aversion raise life expectancy at age 18 , by $1.4 \%$, and higher rates of return on annuity savings delay significantly the age at which life protection peak. Life protection is estimated to add between 1.825 to 4.839 years of life expectancy at age 30 for high school graduates relative to those holding Doctorates, and net "human wealth" has a $25 \%$ higher impact on life expectancy at 18 than non-human wealth. More significantly, our simulations explain $47 \%$ of documented differences in life expectancies of at age 30 across males with high school vs. bachelor degrees. 
The simulations account for $24 \%-33.3 \%$ of the secular growth in average life expectancy at 20 over different periods ending in 1996, just on the basis of the secular growth in real labor earnings and its impact on human and non-human wealth. Based solely on the growth rate of real labor income (1.58\%) observed in our sample, we project life expectancy at age 18 to reach 82.04, or 4.94 added years, by the year 2050 .

Our simulations highlight the existence of significant variations in imputed "values of life saving" $\left(\mathrm{v}^{*}(\mathrm{t})\right)$ by age, by schooling levels, and over time. They also highlight a conceptual difference concerning alternative estimates of VLS, based on the time interval length over which the VLS are projected. The VLS estimates we simulate based on compensating wage differentials for assuming higher risks of mortality over a one-year time interval $\left(\mathrm{V}^{*}(\mathrm{t})\right)$, exhibit a relative age profile virtually identical to that of $\mathrm{v}^{*}(\mathrm{t})$, but $84 \%$ higher on average at all ages. They vary between $\$ 1.298$ million for high-school males at age 75 and $\$ 5.965$ million for males with Doctorates at age 40 in 1996 dollars.

While our estimates of both $\mathrm{v}^{*}(\mathrm{t})$ and $\mathrm{V}^{*}(\mathrm{t})$ are likely to be understated, since they do not account for utility benefits life protection imparts through reduced morbidity, their range of variation appears to rationalize a good part of the huge disparities in private VLS estimates obtained via regression analyses of occupational data. ${ }^{20}$ Our paper offers a theoretical methodology by which such age-specific disparities can be assessed.

The feasibility and stability of our simulations open up opportunities for further extensions of our model to assess more fully the dynamic role of different means of life protection under different insurance setups, and to provide a more complete numerical analysis of the trends and diversities in life expectancies and values of life saving. We leave such extensions to future work. 


\section{REFERENCES}

AHRQ (1996), Medical Expenditure Panel Survey [MEPS], the Agency for Healthcare Research and Quality, Rockville, MD.

Bacci, Guido (1965), Sex Determination. Oxford New York: Pergamon Press.

Barlow, R. and B. Vissandjee (1999), "Determinants of National Life Expectancy", Canadian Journal of Development Studies, Vol. XX No. 1, 9-29.

Davies, James B. (1981), "Uncertain Lifetime, Consumption, and Dissaving in Retirement",Journal of Political Economy, Vol. 89 (3), 561-577.

Ehrlich, I (2000), "Uncertain Lifetime, Life protection, and the Value of Life Saving", Journal of Health Economics, Vol. 19(3), 341-367.

Ehrlich, I. and H. Chuma (1990), “The Demand for Longevity, and the Value of Life Extension", Journal of Political Economy, 98, 761-82.

Forster, M. (2001), "The Meaning of Death: Some Simulations of a Model of Healthy and Unhealthy Consumption", Journal Of Health Economics, (20)4, 613-638.

Gerdttham, U.G., Johannesson, M., Lunndberg, L. and Isacson, D. (2000), “The Demand for Health: Results From New Measures of Health Capital”, European Journal of Political Economy, Vol. 15, 501-521.

Goldman, D. and D. Lakdawalla (2001), "Understanding Health Disparities Across Education Groups", NBER Working Paper \#8328.

Grossman, M., (1972), The Demand for Health: A Theoretical and Empirical Investigation (Columbia University Press, New York).

Harvey, J. (1998), "Estimating OSHA compliance costs", Policy Science, 31, 321-341.

Johansson, P. (2001), "Is There a Meaningful Definition of the Value of a Statistical Life?" Journal of Health Economics, 20, 131-139.

Kydland, F. E. and E. C. Prescott (1982), "Time to Build and Aggregate Fluctuations", Econometrica, 50(6), 1345-1370.

Mitchell. O. (2001), "Developments in Decumulation: The Role of Annuity Products in Financing Retirements", NBER working paper 8567.

Nachtrieb, L. (2003), "Food and Nutrition Information - Fact or Fiction", Nutrition Times 
Philipson, T. and G. Becker (1998), "Old-Age Longevity and Mortality-Contingent Claims", The Journal of Political Economy, 106(3), 551-573.

Richards, H. and R. Barry (1998), "U.S. Life Tables For 1990 By Sex, Race, and Education", Journal of Forensic Economics, 11(1), 9-26.

Shepard, D.S., and Zeckhauser, R.J. (1984), "Survival versus Consumption". Management Science, 30, pp. 424-439.

Thaler, R., and Rosen, S. (1975), "The Value of Saving a Life: evidence from the labor market”. In Terleckyj, N. (Ed.), Household Production and Consumption. Columbia University Press, New York, pp. 265-298.

U.S. Census Bureau, "Historical Income Tables - People, (Table) P-1, Total CPS Population and Per Capita Money Income: 1967 to 1998”, published April, 2000. $<$ http://www.census.gov/hhes/income/histinc/p01.html $>$ [USCB]

U.S. Census Bureau (1998), Statistical Abstract of the United States. [SAUS]

U.S. Department of Health and Human Services, Vital and Health Statistics, Series 2: Data Evaluation and Methods Research, No. 129, 1999. [VS]

U.S. Department of Health and Human Services, National Vital Statistics Report, Various Volumes.

Viscusi, W. K. (1993), "The Value of Risks to Life and Health", Journal of Economic Literature, 31, 1912-46.

Viscusi, W. K. and J. E. Aldy (2003), "The Value of a Statistical Life: A Critical Review of Market Estimates Throughout the World”, NBER Working Paper \#9487. 


\section{FOOTNOTES}

1 A recent exception is Goldman and Lakdawalla (2001) who analyze trends in the diversity of mortality risks by age and education, based on a static model of the demand for health.

2 Viscusi and Aldy (2003) also emphasize the importance of recognizing variations in private VLS by age, but do not offer a formal model in this context.

3 This specification of the output of life protection, $I(t)$, measured in units of $f(t)$, abstracts from any dependence of the productivity of life-protective inputs on the scale of $\mathrm{j}(\mathrm{t})$ because the direction of such effect is not clear a-priori; any assumed non-neutrality would thus be arbitrary. Also, allowing for such interaction would rule out the derivation of conditional closed-form solutions of the model, which greatly facilitate our simulations. We use an aggregate measure of $\mathrm{I}(\mathrm{t})$, and a corresponding cost function, on the implicit assumption that spending on specific inputs $\left\{\mathrm{m}_{\mathrm{j}}, \mathrm{M}_{\mathrm{j}}\right\}$ is allocated optimality to obtain the same marginal increase in $\mathrm{I}(\mathrm{t})$, or reduction in the hazard rate. Note that identifying $\mathrm{M}(\mathrm{t})$ as "preventive" care makes "remedial" care part of consumption, $\mathrm{Z}(\mathrm{t})$; the latter is conceived of as compulsory to prevent morbidity from becoming life threatening.

4 As in deterministic models of health following Grossman (1972) and Ehrlich \& Chuma (1990), we do not model education as endogenously determined with life protection. Since our simulations use age 18 or 25 as reference points, however, completed education may be viewed as predetermined. In our simulations we relax somewhat this "Ben-Porath neutrality" assumption by allowing for a range of deviations of c about its "neutral" level.

5 However, these cross-sectional data do not allow for any adjustments to mortality data due to "cohort effects".

6 This estimate is based on the assumed cost function of life protection in equation (A.2), setting the parameter $\alpha=2$, and estimates of actual spending on life protection from all sources, discussed below. The actual cost parameter used in the simulations is $3.4 \times 10^{8}$. This parameter implies that the cost of a "one-unit" reduction in $\mathrm{I}(\mathrm{t})$, hence in the mortality rate from its biological level ( 0.01 or $11 \%$ of the average fatality rate over the life cycle) is 34,000 dollars.

7 We have arrived at this figure as follows: after smoothing the reported medical expenditure for different ages (which are quite noisy) over 10-year intervals, we find the average annual medical care spending per person in the age interval $40-49$ to be $\$ 1703.67$ in 1996, which is the year of our sample. The preventive care portion of total spending on each of the categories reported in the MEPS data was then arrived at adding all "primary care", and $50 \%$ of all "secondary care", spending totaling $\$ 788.22$, or $46.27 \%$ of total medical care (We are indebted to Dr. Michelle Ehrlich of the Cleveland Clinic for providing these preventive care assessments by categories of care.). 
8 Our Harvey-based lower-bound OSHA annual cost estimate is \$300 for 1996. Nachtrieb (2003) bases her figures on NIH studies. The annual "diet" costs, including food supplements, are extrapolated as \$173.38 in 1996, and exercise costs are assessed to be approximately equal. These are lower-bound assessments of all "life-style" measures of life protection. Adding these spending items to the preventive care figure produces a combined annual estimate of $\$ 1,434.98$ for life protection spending. The projected total spending on life protection, based on the calibrated simulation for our benchmark group, is quite close: $\$ 1,433.32$. We do not incorporate time costs involved in specific life protection activities since no reliable estimates exist, and our earnings estimate is confined to market earnings.

9 Theoretically, our model allows for variations in $n(t)$ over the life cycle. While preference for bequest may change in accordance with the individual's marital or family status, any assumed changes in the life-cycle pattern of $n(t)$ would be rather speculative in the context of the present formulation, which is why we set $\mathrm{n}$ to be constant.

10 This figure is a conservative estimate of the real return on a total portfolio consisting of $50 \%$ treasury bills, $25 \%$ government bonds, and 25\% S\&P 500 stocks over the 50-year period preceding 1996 where the corresponding yields were $1.33 \%, 2.14 \%$, and $8.08 \%$. Davies (1981) is using a similar real rate of return estimate.

11 SAUS data for 1995 and 1998 imply that the median non-human wealth of a 65 years old family head is $\$ 343,197$ in 1996 (using the annual growth rate of $14.09 \%$ for median wealth between 1995 and 1998). This produces a mean value of $\$ 473 \mathrm{~K}$ on the assumption that wealth, like earnings, is log-normally distributed with a median of $\$ 343 \mathrm{~K}$ and a dispersion value of 0.8 (derived via a grid search that produces comparable values of the mean and the standard deviation of the wealth distribution.) In 1996 we also project the "social security wealth" of an average family head to be $\$ 175,698$ at age 65 . This estimate is obtained by discounting the annual benefit stream of $\$ 16,614$ for a 65 years old recipient over the following 12 years (i.e., through life expectancy) at the reported $2 \%$ yield on social security taxes. The total mean wealth level thus computed is $\$ 659 \mathrm{~K}$, which is comparable to our model's projection. Our projected mean wealth and social security wealth at age 65 are quite close: $\$ 694.92$ and $\$ 165.79 \mathrm{~K}$ (see section IV.C.2). They are also close to those in Mitchell (2001), \$625K and 174K, respectively.

12 Note that life expectancy is less than proportionally related to survival risks, because of both the effect of discounting for survival, and the fixed planning horizon D.

13 Our model assumes that annuities and life insurance are traded at actuarially fair terms. In reality, the existence of loading terms due to transaction costs implies that the premium charged on life insurance and borrowing becomes $(1+\mathrm{g}) \mathrm{f}(\mathrm{t})$, while the risk premium paid on annuities becomes $(1-\mathrm{g}) \mathrm{f}(\mathrm{t})$. No conditional closed-form solutions of our model exist in this case, which is why we do not attempt to impute the effect of loading in this paper. Ehrlich (2000, section 6) has shown, however, that while actuarially fair insurance markets produce higher VLS, hence life expectancies, compared to a world with no such markets, 
actuarially unfair insurance markets have an ambiguous impact on these variables, essentially because of conflicting effects on annuities and life insurance.

14 The value of $\mathrm{c}$ has been calibrated based on personal outlays on preventive life protection (see section III.C) and an assumed value of $\alpha$. Consequently, when we vary $\alpha$ in this experiment, we also reconfigure the calibrated value of $\mathrm{c}$ to make the comparison relevant.

${ }^{15}$ For age groups beyond 80 , where we do not have reported market earnings, we maintain the same $25 \%$ and $50 \%$ increments applied to the reported earnings at age 80 .

${ }^{16}$ We conducted similar analyses to explain cross-group differences in life expectancies for different gender and racial groups, which also indicated the model's potential explanatory power. We do not report these results since the data available for calibrating these groups' specific parameters are comparatively more limited.

17 To the extent that persons with higher schooling are self-selected by virtue of their higher (endowed) survival probabilities, our assumed common $\mathrm{j}(\mathrm{t})$ density for all schooling groups understates our projected life expectancies especially for those with higher educational attainments.

18 Data exigencies preclude an application of our model to explain also trends in the diversity of age-specific life expectancies of different population groups over time.

${ }^{19}$ Note that the mortality probability, $\mathrm{p}(\mathrm{t}, \mathrm{t}+\varepsilon)$ is by definition $1-\mathrm{S}(\mathrm{t}, \mathrm{t}+\varepsilon)$, where $S(t, t+\varepsilon)=\exp \left[-\int_{t}^{t+\varepsilon} f(u) d u\right]$ by the Poisson law. We can show that our time-interval estimate of VLS, $\mathrm{V}^{*}(\mathrm{t} ; \varepsilon)=\Delta \mathrm{w} * / \Delta \mathrm{p}$, evaluated over an interval length $\varepsilon$, would approach a point estimate of VLS, dw*/dj $[\mathrm{J}(\mathrm{t})$ held constant $]=-[\partial \mathrm{J}(\mathrm{t}) / \partial \mathrm{j}] /[\partial \mathrm{J}(\mathrm{t}) / \partial \mathrm{w}]=\mathrm{v}^{*}(\mathrm{t})$ in equation (A.6), as $\varepsilon \rightarrow 0$. While $\Delta \mathrm{w}^{*}$ is naturally approximated by $\left(\mathrm{dw}^{*} \times \varepsilon\right)$, however, a Taylor approximation of $\Delta p(t, t+\varepsilon)$ can be shown to always fall short of $\Delta j=(d j \times \varepsilon)$, as long as $\varepsilon>0$. The reason is that $\mathrm{dp}(\mathrm{t}, \mathrm{t}+\varepsilon)$ measures a change in probability, not in a density function. Thus $\mathrm{V}^{*}(\mathrm{t} ; \varepsilon)=\Delta \mathrm{w}^{*} / \Delta \mathrm{p}$ overstates $\mathrm{v}^{*}(\mathrm{t})=\Delta \mathrm{w}^{*} / \Delta \mathrm{j}=\left(\mathrm{dw}^{*} \times \varepsilon\right) /(\mathrm{dj} \times \varepsilon)$ over any positive time interval $\varepsilon$. Moreover, the difference between $\mathrm{V}^{*}(\mathrm{t})$ and $\mathrm{v}^{*}(\mathrm{t})$ is an increasing function of the interval length, $\varepsilon$

${ }^{20}$ Viscusi (1993) survey reports the range of regression estimates applying the WTP approach using labor market data to be $\$ 0.6$ million to $\$ 16.2$ million. In contrast, the range of reported regression estimates using non-labor data is $\$ .1$ to $\$ 4$ million. 


\section{APPENDIX A}

\section{Model specification}

The formal model follows Ehrlich (2000, section 5). The stochastic probability law governing the 'force of mortality', the definitions of the control and state variables, and the utility, 'life-protection' production, and cost functions are discussed in the text. The maximized expected utility function in this formulation is:

(A.1) $J(A(t), t ; \eta)=\operatorname{Max}_{Z, B, I} E\left\{\int_{t}^{\tilde{D}} \exp [-\rho(s-t)] U(Z(s)) d s+\exp [-\rho(\tilde{D}-t)] V(B(\tilde{D}), t)\right\}$

where $\widetilde{D}$ denotes the stochastic time of death, $\rho$ an inter-temporal discount factor, and $\eta$ is vector of our model's parameters, subject to wealth constraints:

(A.2) $\stackrel{0}{\mathrm{~A}}(\mathrm{t})=(\mathrm{r}+\mathrm{f}(\mathrm{t})) \mathrm{A}(\mathrm{t})+\mathrm{w}(\mathrm{t}) \mathrm{h}(\mathrm{t})-\mathrm{cI}^{\alpha}(\mathrm{t})-\mathrm{Z}(\mathrm{t})-\mathrm{f}(\mathrm{t}) \mathrm{B}(\mathrm{t})$,

(A.3) $0 \leq \mathrm{B}(\mathrm{t}) \leq \mathrm{A}(\mathrm{t})+\mathrm{L}(\mathrm{t}) \geq 0$,

and boundary conditions:

(A.4) $\mathrm{J}(\mathrm{A}(\mathrm{D}), \mathrm{D} ; \eta)=\mathrm{V}\left(\mathrm{B}^{*}(\mathrm{D}), \mathrm{D}\right)=\mathrm{V}(\mathrm{A}(\mathrm{D}), \mathrm{D})$ and $\mathrm{A}(\mathrm{D}) \geq 0$.

In equation (A.2)-(A.4), A(t) denotes the current value of non-human wealth,

(A.2a) $A(t)=\exp (r t+m(0, t))\left\{A(0)+\int_{0}^{t} \exp (-r u-m(0, u))\left[w h(u)-\mathrm{cI}^{\alpha}(u)-Z(u)-f(u) B(u)\right] d u\right\}$,

where $\mathrm{m}(0, \mathrm{u})=\int_{0}^{\mathrm{u}} \mathrm{f}(\mathrm{s}) \mathrm{ds}, \mathrm{w}(\mathrm{t})=$ the wage rate, $\mathrm{h}(\mathrm{u})=$ healthy (labor) time, $\mathrm{L}(\mathrm{t})=$ net human wealth, i.e.,

(A.3a) $\mathrm{L}(\mathrm{t})=\int_{t}^{D} \exp [-\mathrm{r}(\mathrm{u}-\mathrm{t})-\mathrm{m}(\mathrm{t}, \mathrm{u})]\left[\mathrm{w}(\mathrm{u}) \mathrm{h}(\mathrm{u})-\mathrm{cI}^{\alpha}(\mathrm{t})\right] \mathrm{du}$, where $\mathrm{m}(\mathrm{t}, \mathrm{u}) \equiv \int_{\mathrm{t}}^{\mathrm{u}} \mathrm{f}(\mathrm{s}) \mathrm{ds}$,

and $\mathrm{D}$ denotes the terminal date of the planning horizon that must be used to solve our stochastic dynamic program. Its determination is discussed in section III.E in the text.

By the stochastic dynamic programming approach, the solution must satisfy 
(A.5) $-J_{t}=-\rho J+U\left(Z^{*}\right)+J_{A}\left[(r+f) A+w(t) h(t)-\mathrm{cI}^{\alpha}(t)-Z^{*}-f B^{*}\right]+f\left[V\left(B^{*}, t\right)-J\right]$,

where $\mathrm{J}_{\mathrm{t}} \equiv \partial \mathrm{J}(\mathrm{A}(\mathrm{t}), \mathrm{t} ; \eta) / \partial \mathrm{t}$.

The optimal control variables $\mathrm{I}^{*}, \mathrm{Z}^{*}$, and $\mathrm{B}^{*}$ are then solved from

(A.6) $\left[\alpha c I(t)^{\alpha-1}\right]^{*}=\left[\partial J_{t} / \partial f\right] / J_{A}=\left(1 / J_{A}\right)\left[J(A(t), t ; \eta)-V\left(B^{*}\right)\right]+B^{*}-A \equiv v^{*}(t)$

(A.7) $U_{Z}\left(Z^{*}\right)=J_{A}$

(A.8) $\mathrm{B}^{*}=0$ if $\mathrm{J}_{\mathrm{A}}>\mathrm{V}^{\prime}\left(\mathrm{B}^{*}\right)$

$\varepsilon(0, A(t)+L(t))$, if $J_{A}=V^{\prime}\left(B^{*}\right)$

$\mathrm{A}(\mathrm{t})+\mathrm{L}(\mathrm{t})$, if $\mathrm{J}_{\mathrm{A}}<\mathrm{V}^{\prime}\left(\mathrm{B}^{*}\right)$,

where (A.6) is also the solution for the shadow price of life protection, or VLS.

\section{Conditional Explicit Solutions}

No explicit solutions can be obtained for the system (A.6)-(A.8). To obtain a conditional closed-form solution for the maximized life-time expected utility function $\mathrm{J}_{1}$ in equation (A.1), the instantaneous utility of consumption function is first specialized to exhibit 'constant relative risk aversion',

(A.9) $\mathrm{U}(\mathrm{Z})=(1 / \mathrm{k}) \mathrm{Z}^{\mathrm{k}}$,

where $0<\mathrm{k}<1$ to assure concavity, and $\mathrm{d}=(1-\mathrm{k})$ denotes the degree of relative risk aversion. The utility of bequest function is similarly specialized as (A.10) $\mathrm{V}(\mathrm{B}, \mathrm{t})=[\mathrm{n}(\mathrm{t}) / \mathrm{k}] \mathrm{B}^{\mathrm{k}}$,

with $n(t)$ representing the intensity of utility derived by the individual from capital to be bequeathed to heirs. Finally, the optimal consumption and bequest choices are now taken to be conditional on a predetermined path of optimal self-protection outlays.

These simplifications permit an explicit solution for the partial differential equation (A.5), conditional on an optimal path of self-protection inputs (I), i.e., taking the 
age-specific density of mortality rates $f(t)$ as given.. The solution can be shown equal to (A.11) $J(A(t), t ; \alpha)=[a(t) / k][A(t)+L(t)]^{k}$.

where $a(t)$ represents the marginal expected utility of a unit of wealth while one is alive. It s solution is given by

$$
\text { (A.12) }[\mathrm{a}(\mathrm{t})]^{(1 / \mathrm{d})}=\exp \left\{-\int_{\mathrm{t}}^{\mathrm{D}} \mathrm{x}(\mathrm{u}) \mathrm{du}\right\}[\mathrm{n}(\mathrm{D})]^{(1 / \mathrm{d})}+\int_{\mathrm{t}}^{\mathrm{D}} \mathrm{y}(\mathrm{u}) \exp \left\{-\int_{\mathrm{t}}^{\mathrm{u}} \mathrm{x}(\mathrm{s}) \mathrm{ds}\right\} \mathrm{du},
$$

where $x(u) \equiv f(u)+[(\rho-r k) /(1-k)]$, and $y(u) \equiv 1+f(u)[n(u)]^{(1 / d)}$.

Equations (A.11) and (A.12) provide an explicit solution for the indirect expected utility of the remaining life span, conditional on optimal self-protection inputs $\left(I^{*}(t)\right)$. By exploiting equations (A.6), (A.7), (A.8), and (A.11), we can obtain similarly conditional explicit solutions for the co-state variable $\mathrm{v}^{*}(\mathrm{t})$, or the value-of-life-saving function, and the optimal values of consumption and bequest as follows:

$(A .13) v^{*}(t)=(1 / k) L(t)+[(1-k) / k]\left[A(t)-B^{*}(t)\right]=z(t)[A(t)+L(t)]-A(t)=\alpha c I^{*}(t)^{\alpha-1}$

where $\mathrm{z}(\mathrm{t})=[\mathrm{n}(\mathrm{t}) / \mathrm{a}(\mathrm{t})]^{(1 / \mathrm{d})}+(1 / \mathrm{k})\left\{1-[\mathrm{n}(\mathrm{t}) / \mathrm{a}(\mathrm{t})]^{(1 / \mathrm{d})}\right\}>1($ see Ehrlich 2000, p.357)

(A.14) $Z^{*}(t)=[1 / a(t)]^{(1 / d)}[A(t)+L(t)]$, and

(A.15) $\mathrm{B}^{*}(\mathrm{t})=[\mathrm{n}(\mathrm{t}) / \mathrm{a}(\mathrm{t})]^{(1 / \mathrm{d})}[\mathrm{A}(\mathrm{t})+\mathrm{L}(\mathrm{t})]$.

Equation (A.13) indicates the greater importance of human $(L(t))$, relative to nonhuman $(\mathrm{A}(\mathrm{t}))$ wealth in affecting the value of life saving. For a detailed interpretation of this result see Ehrlich (op. cit.).

\section{Unconditional Solutions}

Using the explicit solutions (A.13)-(A.15) and the first order condition for the optimal self-protection (A.6), an unconditional solution to all three control variables of the model, and thus for the model's co-state and state variables as well, can be found through the iterative procedure described in the text and in Appendix B. 


\section{APPENDIX B}

The iteration procedure we use is similar to Newton's method, except that we do not use the system's Jacobian matrix to enhance the convergence speed. All the relevant numerical integrations are carried out using the Simpson method. The iterations involve the following steps:

- Step A: Initialize a path of life-protection efforts, $\mathrm{I}(\mathrm{t})$. In the benchmark case proceed to step B. In our calibrated simulations we use the initialized $I(t)$ to construct $f(t)$ from previously projected $j(t)$, subject to $f(t) \geq 0$, and then proceed to obtain $m(i, j) \equiv \int_{i}^{j} f(t) d t$ through numerical integration.

- Step B: Calculate by numerical integration the factor a(t) - a component of the intensity of the optimal value function (A.11) - using its definition in eq. (A.12) of Appendix A. This calculation is done on the basis of the computed values of $f(t)$ and $\mathrm{m}(\mathrm{i}, \mathrm{j})$, and subject to our calibrated values for the other basic parameters of the model: the real rate of interest, $r$, the rate of time preference, $\rho$, the intensity of bequest preference, $\mathrm{n}$, and the degree of relative risk aversion, 1-k.

- Step C: Calculate financial wealth $\mathrm{A}(\mathrm{t})$, bequest $\mathrm{B}(\mathrm{t})$, consumption $\mathrm{Z}(\mathrm{t})$, and net human wealth $\mathrm{L}(\mathrm{t})$ (the discounted labor income net of the cost of self-protection) as follows:

$\underline{\mathrm{C} 1}$ : Given $\mathrm{I}(\mathrm{t})$ and $\mathrm{f}(\mathrm{t})$, calculate $\mathrm{L}(\mathrm{t})$ by numerical integration using equation (A.3a) in Appendix A.

C2: Calculate $\mathrm{Z}(\mathrm{t})$ and $\mathrm{B}(\mathrm{t})$. As in Ehrlich (2000) equation (3.7a), Z(t) has a growth rate of $(r-\rho) /(1-k)$, and from (A.14), Z(0) can be determined by $A(0), a(0)$, and $L(0)$. $\mathrm{B}(\mathrm{t})$ can be similarly calculated, given the assumed value of the intensity of bequest preferences, since by equations (A.14) and (A.15) $B(t)=n(t)^{1 /(1-k)} Z(t)$.

C3: Given the solutions to $\mathrm{Z}(\mathrm{t}), \mathrm{L}(\mathrm{t})$ and $\mathrm{a}(\mathrm{t})$, we can use (A.14) to solve for $\mathrm{A}(\mathrm{t})$.

- Step D: Calculate the value of life saving $\mathrm{V}^{*}(\mathrm{t})$, thus life-protection expenditures $\mathrm{I}(\mathrm{t})$, as given in equation (A.13), using $\mathrm{A}(\mathrm{t}), \mathrm{B}(\mathrm{t})$, and $\mathrm{L}(\mathrm{t})$ from the previous step.

- Step E: Compare I(t), as calculated in Step D, with the preceding path of $I(t)$. (In the first round, the "preceding path" is the initialized path). Define diff $=\operatorname{Max}_{t}[\mathrm{II}(\mathrm{t})$ $\left.I^{0}(t) \mid / I^{0}(t)\right]$, where $I^{0}(t)$ is the preceding path of $I(t)$, i.e., diff is the maximum percentage change in $\mathrm{I}(\mathrm{t})$. If diff $<$ tol, where tol is some pre-specified tolerance level, the system converges, and you may report the results. If diff $>$ tol, record the current new $\mathrm{I}(\mathrm{t})$ as the previous path of $\mathrm{I}(\mathrm{t})$ and proceed to Step $\mathrm{C}$. The tolerance level we have chosen for tol is $10^{-5}$. 
Table 1: Calibrated Simulations of Life-Protection Choices in our Baseline Case (1996 data) Conditional on survival to:

\begin{tabular}{|c|c|c|c|c|c|}
\hline \multirow[t]{2}{*}{ Age 18} & \multicolumn{2}{|c|}{ Peak of $v^{*}(t)$} & \multirow[t]{2}{*}{ Age 65} & \multicolumn{2}{|c|}{ Actual life expectancy at 18} \\
\hline & Age & $\begin{array}{c}\text { Value of } \\
v^{*}(t)\end{array}$ & & Age & $\begin{array}{c}\text { Value of other } \\
\text { variables }\end{array}$ \\
\hline \multicolumn{6}{|c|}{ 1a. Remaining Actual Life Expectancy $\mathbf{T}^{*}(t)^{\#}$} \\
\hline 59.08 & & & 17.58 & & \\
\hline \multicolumn{6}{|c|}{ 1b. Net Human Wealth L(t) (in \$K)* } \\
\hline 610.27 & 38 & 653.52 & 234.21 & 77 & 43.37 \\
\hline \multicolumn{6}{|c|}{ 1c. Non-Human Wealth A(t) (in \$K)* } \\
\hline 6.50 & 38 & 172.80 & 694.92 & 77 & 793.41 \\
\hline \multicolumn{6}{|c|}{ 1d. Value of Life Saving $v^{*}(t)$ (in \$M)* } \\
\hline 1.191 & 38 & 1.435 & 1.090 & 77 & 0.775 \\
\hline \multicolumn{6}{|c|}{ 1e. Expenditure on Life Protection C(t) (in \$ mil.) } \\
\hline 1043.1 & 38 & 1514.1 & 873.1 & 77 & 441.9 \\
\hline \multicolumn{6}{|c|}{ 1f. Observed Mortality Hazard Rates f(t) } \\
\hline 0.0009 & 38 & 0.0019 & 0.0166 & 77 & 0.0445 \\
\hline \multicolumn{6}{|c|}{ 1g. Imputed "Biological" Mortality Hazard rates j(t) } \\
\hline 0.0026 & 38 & 0.0040 & 0.0182 & 77 & 0.0457 \\
\hline \multicolumn{6}{|c|}{ 1h. Impact of Life Protection on "Biological”' Life Expectancy (years) } \\
\hline 3.426 & 38 & 1.614 & 0.249 & 77 & 0.065 \\
\hline \multicolumn{6}{|c|}{ 1i. Impact of Life Protection on “Biological” Life Expectancy (\%) } \\
\hline 6.155 & 38 & 4.172 & 1.435 & 77 & 0.656 \\
\hline
\end{tabular}

Basic parameter set: $\mathrm{k}=0.5, \mathrm{r}=3.2 \%, \rho=1.5 \%, \mathrm{n}=1.2, \alpha=2$, and $\mathrm{c}=3.4$.

* Life Expectancy $\mathrm{T}^{*}(\mathrm{t})$, the actuarially fair values of net human wealth $\mathrm{L}(\mathrm{t})$, non-human wealth $\mathrm{A}(\mathrm{t})$, and value of life saving $\mathrm{v}^{*}(\mathrm{t})$ are defined in Appendix A. Monetary values are in 1996 dollars

\# Remaining actual life expectancy for the benchmark group. 
Table 2: Life Protection's Impact on Life Expectancy and Value of Life Saving (in 1996 million \$). Role of Parameter Changes

\begin{tabular}{|c|c|c|c|c|c|}
\hline \multirow[b]{2}{*}{ Parameter } & \multirow[b]{2}{*}{ Range } & \multicolumn{2}{|c|}{ Impact on Life Expectancy at 18} & \multicolumn{2}{|c|}{ Value of Life Saving at } \\
\hline & & Percentage & Years & Peak Age & Peak Value \\
\hline \multirow{3}{*}{$\mathrm{k}$} & 0.375 & 7.939 & 4.419 & 38 & 1.823 \\
\hline & $0.5^{*}$ & 6.155 & 3.426 & 38 & 1.435 \\
\hline & 0.625 & 5.060 & 2.817 & 38 & 1.186 \\
\hline \multirow{3}{*}{$\mathrm{c}$} & 2.55 & 8.300 & 4.621 & 38 & 1.432 \\
\hline & $3.4 *$ & 6.155 & 3.426 & 38 & 1.435 \\
\hline & 4.25 & 4.890 & 2.722 & 38 & 1.437 \\
\hline \multirow{3}{*}{$\alpha$} & 1.5 & 4.230 & 2.355 & 38 & 1.424 \\
\hline & $2.0 *$ & 6.155 & 3.426 & 38 & 1.435 \\
\hline & 2.5 & 8.015 & 4.462 & 38 & 1.448 \\
\hline \multirow{3}{*}{$\mathrm{r}$} & $2.4 \%$ & 6.242 & 3.475 & 28 & 1.534 \\
\hline & $3.2 \% *$ & 6.155 & 3.426 & 38 & 1.435 \\
\hline & $4.0 \%$ & 6.302 & 3.508 & 55 & 1.523 \\
\hline \multirow{3}{*}{$\mathrm{n}$} & 0.9 & 6.174 & 3.437 & 38 & 1.439 \\
\hline & $1.2 *$ & 6.155 & 3.426 & 38 & 1.435 \\
\hline & 1.5 & 6.131 & 3.413 & 37 & 1.430 \\
\hline \multirow{3}{*}{$\mathrm{w}(\mathrm{t}) * *$} & $\$ 26,658 *$ & 6.155 & 3.426 & 38 & 1.435 \\
\hline & $+25 \%$ & 7.750 & 4.314 & 38 & 1.789 \\
\hline & $+50 \%$ & 9.373 & 5.218 & 38 & 2.141 \\
\hline \multirow{3}{*}{$\mathrm{A}(0) * * *$} & $\$ 6,315 \#$ & 6.155 & 3.426 & 38 & 1.435 \\
\hline & $+25 \%$ & 6.163 & 3.431 & 38 & 1.437 \\
\hline & $+50 \%$ & 6.172 & 3.436 & 38 & 1.439 \\
\hline \multirow{3}{*}{$\mathrm{j}(\mathrm{t})$} & $-25 \%$ & 6.691 & 3.966 & 39 & 1.485 \\
\hline & Original* & 6.155 & 3.426 & 38 & 1.435 \\
\hline & $+25 \%$ & 5.707 & 3.003 & 37 & 1.391 \\
\hline
\end{tabular}

* Denotes our selected benchmark parameter and initial conditions.

** Upward adjustments of $25 \%$ and 50\% are meant to capture alternative "full earnings" levels, adjusted for home production.

*** Upward adjustments designed to be comparable to those for $\mathrm{w}(\mathrm{t})$.

\# $\mathrm{A}(0)$ in the benchmark case is imputed from the bequest choices of the previous generation (see text). 
Table 3: Calibrated Simulations of Life-time Choices in our Benchmark Case Additional Sensitivity Analysis

\begin{tabular}{|c|c|c|c|c|c|c|}
\hline At Age: & 18 & \multicolumn{2}{|c|}{ Peak of $v^{*}(t)$} & \multirow[t]{2}{*}{65} & \multicolumn{2}{|c|}{$\begin{array}{c}\text { Actual life expectancy at } \\
18:\end{array}$} \\
\hline Change & & Age & Value of $v^{*}(\mathrm{t})$ & & Age & $\begin{array}{l}\text { Value of other } \\
\text { variables }\end{array}$ \\
\hline
\end{tabular}

A. Approximating the impact of higher (lower) durability of life protection $I(t) b y$ letting I(39) lower (raise) mortality risks by $25 \%$ over 10 years (ages 40-50)

\begin{tabular}{|c|c|c|c|c|c|c|}
\hline \multicolumn{7}{|c|}{ 3A.1 Remaining Projected Life Expectancy } \\
\hline $0 *$ & 59.08 & & & 17.58 & & \\
\hline$-25 \%$ & 59.44 & & & 17.58 & & \\
\hline$-25 \%(10 \%) \#$ & 59.27 & & & 17.58 & & \\
\hline$+25 \%$ & 58.72 & & & 17.58 & & \\
\hline$+25 \%(10 \%) \#$ & 58.88 & & & 17.58 & & \\
\hline \multicolumn{7}{|c|}{ 3A.2 Value of Life Saving (in \$M) } \\
\hline $0^{*}$ & 1.191 & 38 & 1.435 & 1.090 & 77 & 0.775 \\
\hline$-25 \%$ & 1.197 & 38 & 1.448 & 1.088 & 78 & 0.743 \\
\hline$-25 \%(10 \%) \#$ & 1.194 & 38 & 1.442 & 1.089 & 77 & 0.774 \\
\hline$+25 \%$ & 1.185 & 37 & 1.423 & 1.092 & 77 & 0.777 \\
\hline$+25 \%(10 \%) \#$ & 1.188 & 38 & 1.428 & 1.091 & 77 & 0.776 \\
\hline \multicolumn{7}{|c|}{ 3A.3 Expenditure on Life Protection } \\
\hline $0 *$ & 1043.1 & 38 & 1514.1 & 873.1 & 77 & 441.9 \\
\hline$-25 \%$ & 1053.3 & 38 & 1540.7 & 870.2 & 78 & 405.8 \\
\hline$-25 \%(10 \%) \#$ & 1048.9 & 38 & 1529.0 & 871.7 & 77 & 441.0 \\
\hline$+25 \%$ & 1033.0 & 37 & 1488.1 & 876.1 & 77 & 443.7 \\
\hline$+25 \%(10 \%) \#$ & 1037.3 & 38 & 1499.4 & 874.5 & 77 & 442.7 \\
\hline
\end{tabular}

B. Simulations adjusted to reflect the role of PAYG Social Security

\begin{tabular}{|c|c|c|c|c|c|c|}
\hline \multicolumn{7}{|c|}{ 3B.1 Projected Remaining Life Expectancy } \\
\hline Unadjusted* & 59.10 & & & 17.58 & & \\
\hline Adjusted $* *$ & 59.14 & & & 17.60 & & \\
\hline \multicolumn{7}{|c|}{ 3B.2 Value of Life Saving (in \$M) } \\
\hline Unadjusted* & 1.191 & 38 & 1.435 & 1.090 & 77 & 0.775 \\
\hline Adjusted** & 1.173 & 40 & 1.442 & 1.228 & 77 & 0.805 \\
\hline \multicolumn{7}{|c|}{ 3B.3 Expenditure on Life Protection } \\
\hline Unadjusted* & 1043.1 & 38 & 1514.1 & 873.1 & 77 & 441.9 \\
\hline Adjusted $* *$ & 1011.4 & 40 & 1528.8 & 1109.1 & 77 & 477.0 \\
\hline
\end{tabular}

Basic parameter set: $\mathrm{r}=3.2 \%, \rho=1.5 \%, \mathrm{n}=1.2$, and $\mathrm{c}=3.4$. Monetary values are in $1996 \$$

\# Assuming a straight-line depreciation of the durability impact

* The unadjusted values are the simulated values for our benchmark case in Table 1

** Simulations adjusted after imposing social security taxes and benefits 
Table 4: Calibrated Simulations of Lifetime Choices by Education (1996 data), Using Imputed Biological Mortalities of Benchmark Group*

\begin{tabular}{|c|c|c|c|c|c|c|}
\hline At Age: & \multirow[t]{2}{*}{30} & \multicolumn{2}{|c|}{ Peak of $v^{*}(t)$} & \multirow[t]{2}{*}{65} & \multicolumn{2}{|c|}{ Life Expectancy at 25} \\
\hline Education & & Age & $\begin{array}{c}\text { Value of } \\
v^{*}(t)\end{array}$ & & Age & $\begin{array}{l}\text { Value of other } \\
\text { variables }\end{array}$ \\
\hline
\end{tabular}

4a. Remaining Projected Life Expectancy using Benchmark Biological Risks

High School

Bachelor

Master

Doctorate

44.41

45.84

46.51

47.42
15.71

15.84

15.91

15.99

4b. Value of Life Saving (in \$M)

\begin{tabular}{c|l|l|l|l|l|l} 
High School & 1.256 & 37 & 1.282 & 0.955 & 74 & 0.743 \\
Bachelor & 2.183 & 38 & 2.245 & 1.651 & 76 & 1.178 \\
Master & 2.651 & 36 & 2.689 & 1.984 & 76 & 1.448 \\
Doctorate & 3.098 & 40 & 3.228 & 2.485 & 78 & 1.577
\end{tabular}

4c. Impact of Life Protection on Life Expectancy (years)

\begin{tabular}{c|l|l|l|l|l|l} 
High School & 1.825 & 37 & 1.335 & 0.180 & 74 & 0.066 \\
Bachelor & 3.256 & 38 & 2.258 & 0.311 & 76 & 0.087 \\
Master & 3.932 & 36 & 2.998 & 0.379 & 76 & 0.107 \\
Doctorate & 4.839 & 40 & 3.041 & 0.467 & 78 & 0.095
\end{tabular}

4d. Impact of Life Protection on Life Expectancy (\%)

\begin{tabular}{c|c|c|c|c|c|c} 
High School & 4.286 & 37 & 3.621 & 1.158 & 74 & 0.639 \\
Bachelor & 7.646 & 38 & 6.265 & 2.001 & 76 & 0.947 \\
Master & 9.235 & 36 & 7.956 & 2.441 & 76 & 1.164 \\
Doctorate & 11.364 & 40 & 8.835 & 3.007 & 78 & 1.153
\end{tabular}

4e. Estimated Remaining Life Expectancies Based on Death Certificates Data

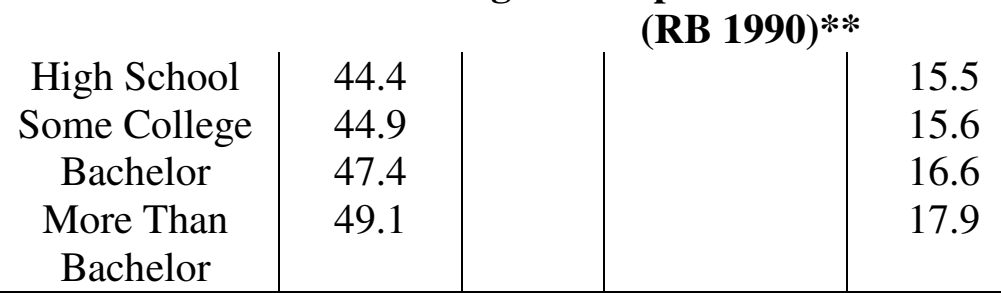

* See notes to Table 1. The benchmark group here is all US males. All monetary values are in 1996 dollars.

** Estimated life expectancies in RB, thus in our simulations, are for males. 
Table 5. Trends in Life Expectancy at Age 20* (through 1996)

\begin{tabular}{|c|c|c|c|c|c|}
\hline & \multicolumn{5}{|c|}{ Year } \\
\hline & 1970 & 1975 & 1980 & 1985 & 1990 \\
\hline \multicolumn{6}{|c|}{ Remaining Life Expectancy } \\
\hline Projected $^{1}$ & 56.10 & 56.35 & 56.60 & 56.82 & 57.04 \\
\hline Projected $^{2}$ & 55.60 & 55.89 & 56.20 & 56.51 & 56.86 \\
\hline Actual & 53.00 & 53.9 & 55.46 & 56.1 & 56.63 \\
\hline \multicolumn{6}{|c|}{ Increase in Life Expectancy from Selected Year to 1996} \\
\hline Projected $^{1}$ & 1.07 & 0.82 & 0.57 & 0.35 & 0.13 \\
\hline Projected $^{2}$ & 1.57 & 1.28 & 0.97 & 0.66 & 0.31 \\
\hline Actual & 4.17 & 3.27 & 1.71 & 1.07 & 0.54 \\
\hline \multicolumn{6}{|c|}{ Percentage Explained } \\
\hline Projected $^{1}$ & 25.66 & 25.08 & 33.33 & 32.71 & 24.07 \\
\hline Projected $^{2}$ & 37.65 & 39.14 & 56.73 & 61.68 & 57.41 \\
\hline
\end{tabular}

* Backward projections based on imputed "biological" mortality rates in 1996. Projections shown at age 20, to make them comparable to actually reported age-specific life expectancies in VS publications. The Basic parameter set is the same as in Table 1.

${ }^{1}$ Based on reported labor earnings for the general population.

${ }^{2}$ Given a $1 \%$ rate of reduction in the real unit cost of life protection, c (based on a $1 \%$ economy-wide TFP growth rate) in addition to actual earnings growth.

Table 6: Age-Specific VLS based on Willingness to Accept Compensating Wage Differentials for Marginally Higher Mortality Risks Over One-Year Intervals $\left(V^{*}(t)\right)$ vs. "Point" Estimates based Willingness to Spend on Life Protection $\left(v^{*}(t)\right)$

\begin{tabular}{c|cccccccc}
\hline Age & $\mathbf{2 0}$ & $\mathbf{2 5}$ & $\mathbf{3 0}$ & $\mathbf{3 5}$ & $\mathbf{3 6}$ & $\mathbf{3 7}$ & $\mathbf{3 8}$ & $\mathbf{3 9}$ \\
\hline \hline $\mathrm{v}^{*}(\mathrm{t})($ in $\$ \mathrm{M})$ & 1.2399 & 1.3369 & 1.3991 & 1.4303 & 1.4330 & 1.4345 & 1.4350 & 1.434 \\
$\mathrm{~V}^{*}(\mathrm{t})($ in $\$ \mathrm{M})$ & 2.3647 & 2.5586 & 2.6451 & 2.6722 & 2.6722 & 2.6740 & 2.6782 & 2.653 \\
\hline Age & $\mathbf{4 0}$ & $\mathbf{4 5}$ & $\mathbf{5 0}$ & $\mathbf{5 5}$ & $\mathbf{6 0}$ & $\mathbf{6 5}$ & $\mathbf{7 0}$ & $\mathbf{7 5}$ \\
\hline $\mathrm{v}^{*}(\mathrm{t})($ in $\$ \mathrm{M})$ & 1.4325 & 1.4078 & 1.3578 & 1.2859 & 1.194 & 1.090 & 0.968 & 0.834 \\
$\mathrm{~V}^{*}(\mathrm{t})($ in $\$ \mathrm{M})$ & 2.6472 & 2.5832 & 2.4722 & 2.2966 & 2.155 & 1.972 & 1.756 & 1.504 \\
\hline
\end{tabular}

The $\mathrm{v}^{*}(\mathrm{t})$ estimates are derived from the simulations reported in Table 1 for detailed ages. $\mathrm{V}^{*}(\mathrm{t})$ are derived by raising the mortality probability over a one-year period by 0.1 per 1000 and estimating the compensating wage differential (in 1996 dollars) required to keep lifetime expected utility at age 18 intact for our benchmark group. 
Figure 1: Calibrated Simulations in Benchmark Case: Maximized Expected Utility

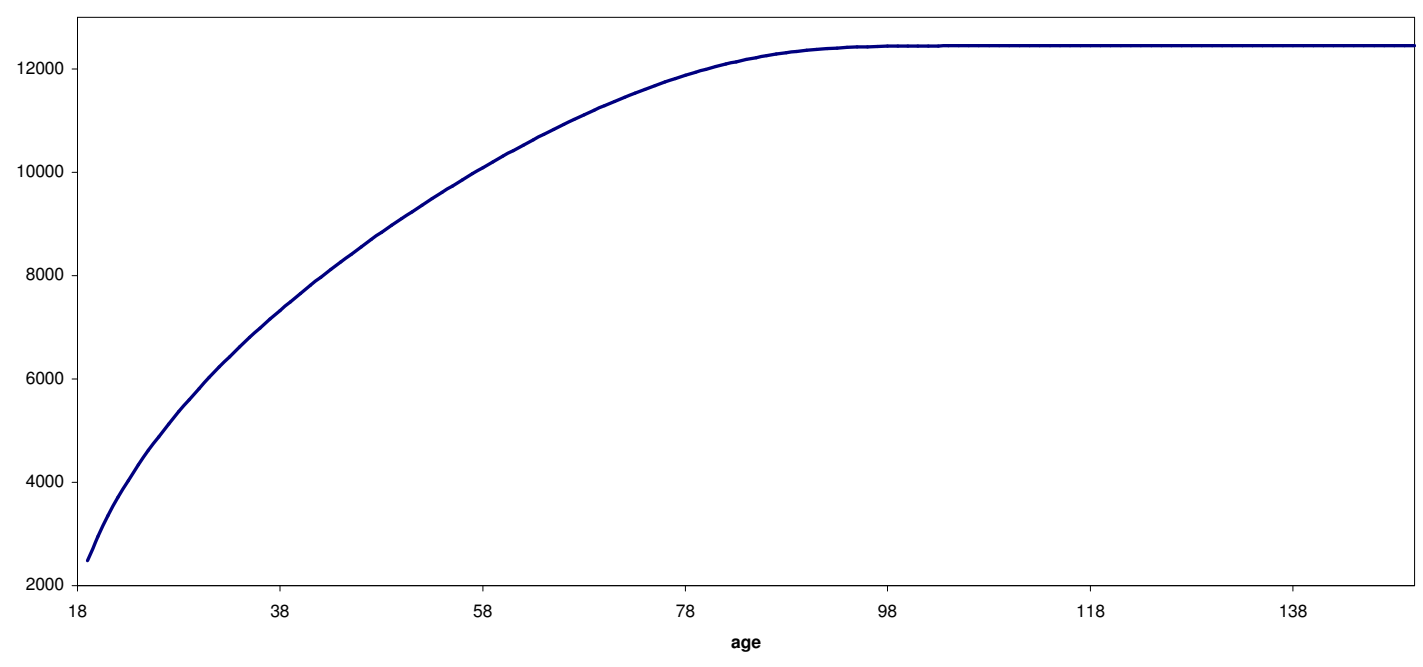

Figure 2: Calibrated Simulations of Benchmark Case: Net Human Wealth (in 100,000 1996 dollars)

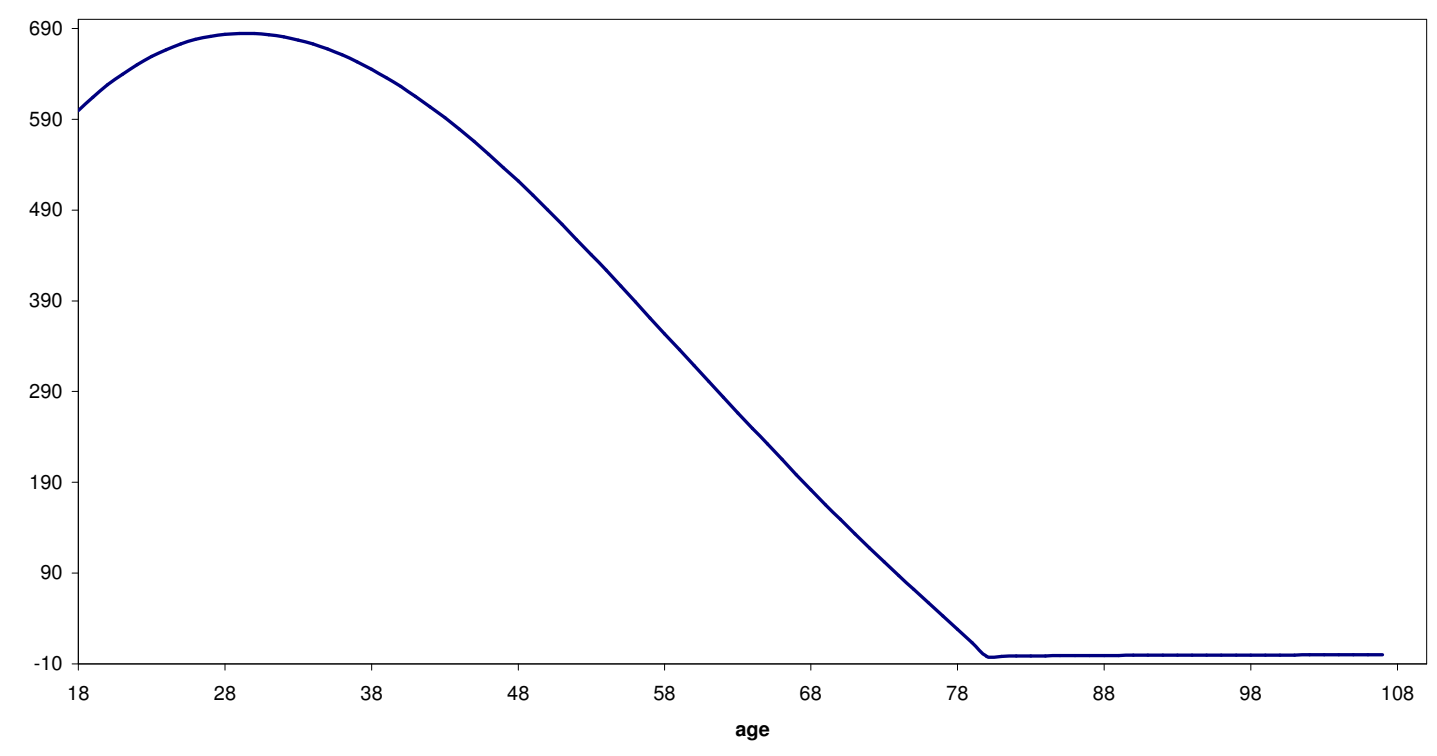


Figure 3: Calibrated Simulations of Benchmark Case: Non-Human Wealth (in 100,000 1996 dollars)

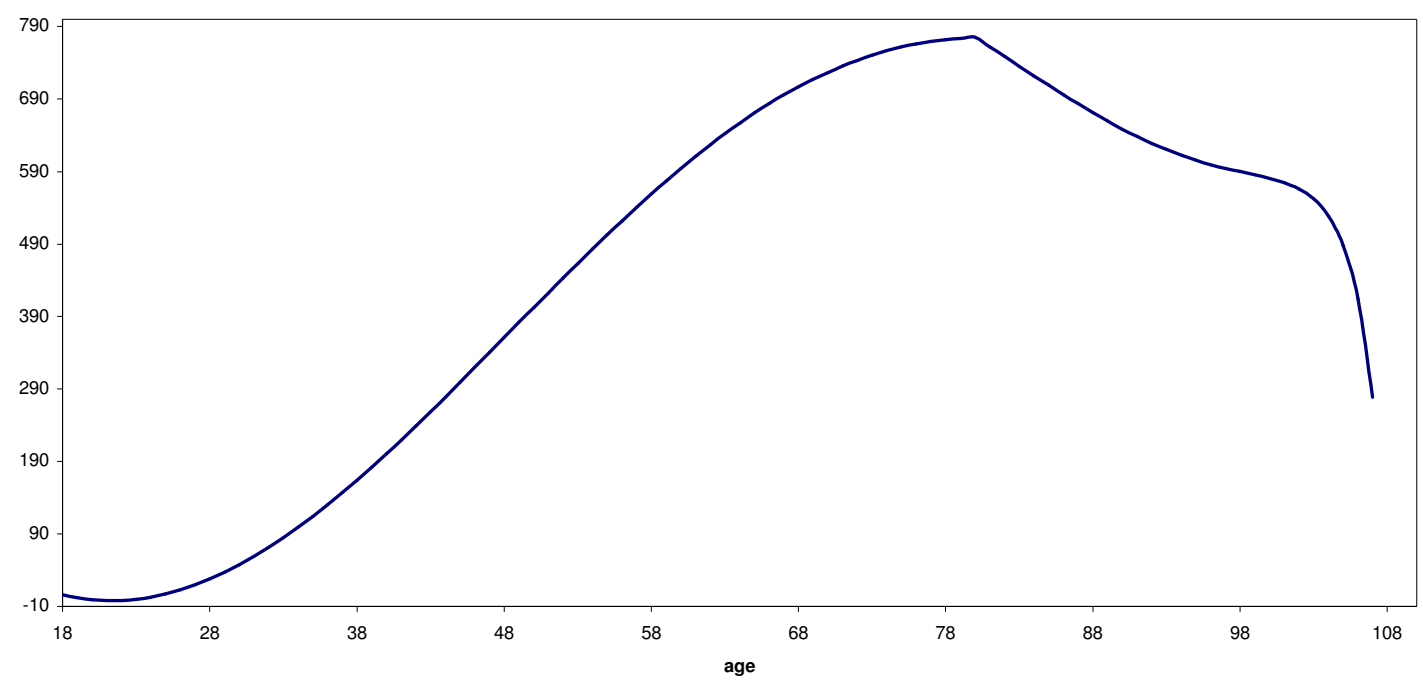

Figure 4: Calibrated Simulations (using Alternative Interest Rates): Value of Life Saving (in million 1996 dollars)

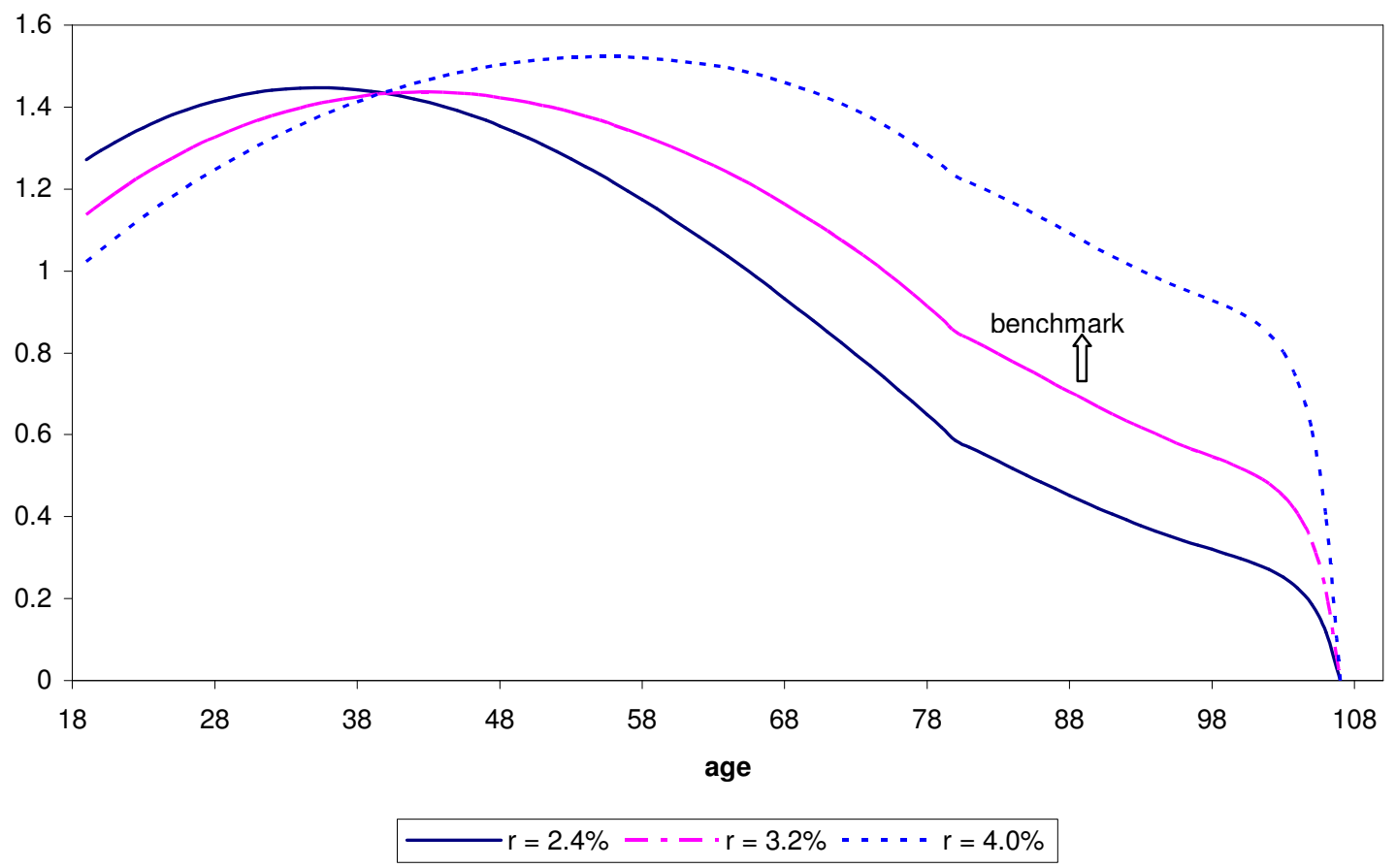


Figure 5: Calibrated Simulations of Benchmark Case: "Biological" v. Observed Mortality Rates

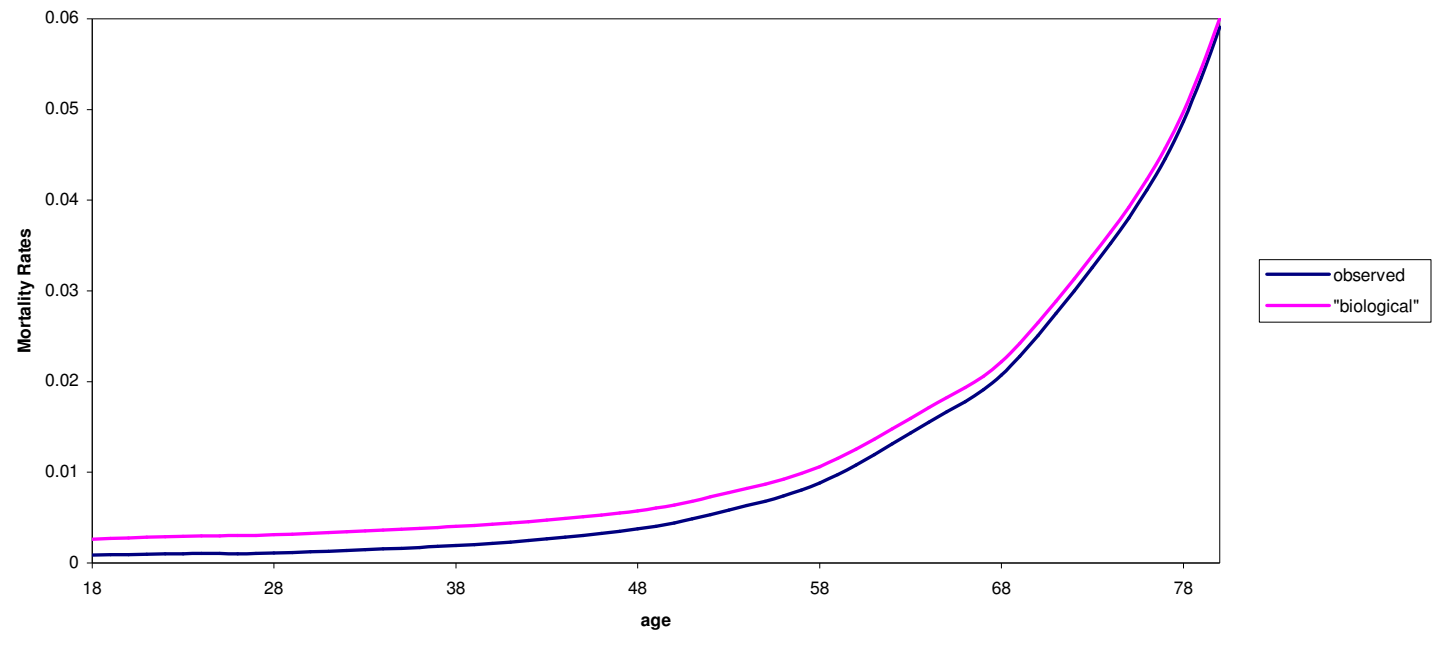

Figure 6: Calibrated Simulations of Benchmark Case: Life Expectancy based on "Biological" v. Observed Mortality Rates

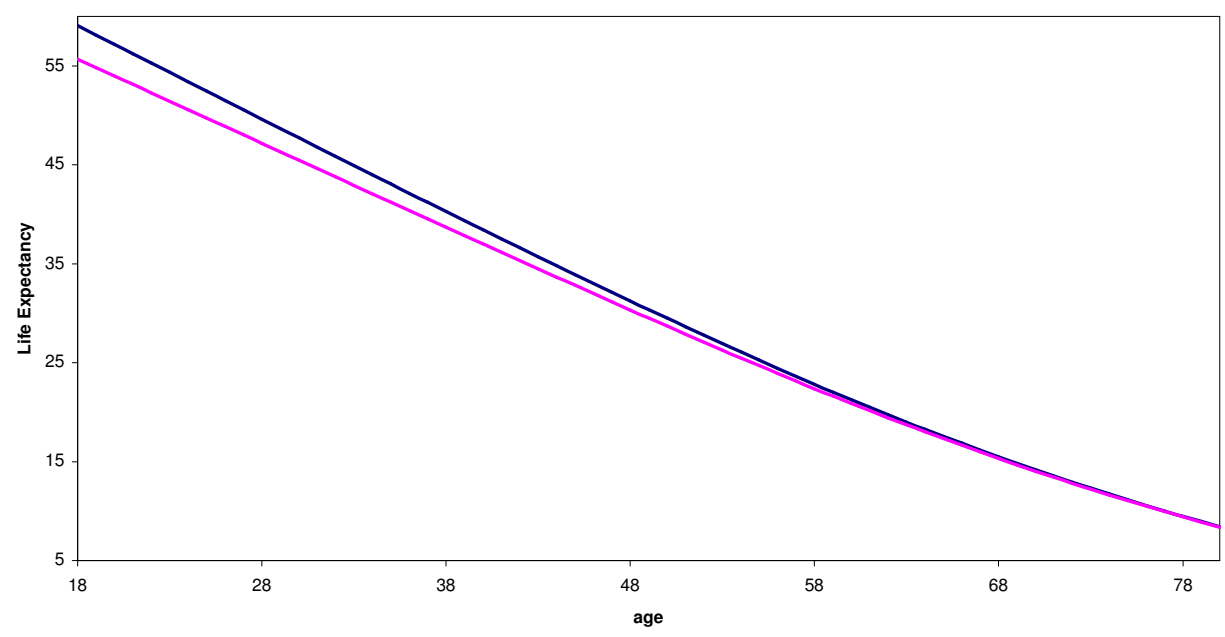

- 